\title{
The Two Arrows of Pain: Mechanisms of Pain Related to Meditation and Mental States of Aversion and Identification
}

\author{
Valentina Nicolardi ${ }^{1,2}$ (1) Luca Simione $^{3} \cdot$ Domenico Scaringi $^{1} \cdot$ Peter Malinowski ${ }^{4} \cdot J_{\text {Juliana Yordanova }}{ }^{5} \cdot$ Vasil Kolev $^{5}$. \\ Federica Mauro $^{1} \cdot$ Fabio Giommi $^{6,7} \cdot$ Henk P. Barendregt $^{8} \cdot$ Salvatore M. Aglioti ${ }^{1,2} \cdot$ Antonino Raffone $^{1,9}$
}

Accepted: 22 November 2021

(c) The Author(s) 2022

\begin{abstract}
Objectives According to the core Buddhist psychology models of the "two arrows of pain" and "co-dependent origination," pain is the resultant of bodily and mental factors, which can be regulated by meditation states and traits. Here we investigated how pain and the related aversion and identification (self-involvement) experiences are modulated by focused attention meditation (FAM), open monitoring meditation (OMM), and loving kindness meditation (LKM), as well as by meditation expertise.

Methods Theravada Buddhist long-term meditators were matched with a group of short-term meditators. Nociceptive electrical stimulation was administered during FAM, OMM, and LKM, and in a non-meditative rest condition. Experience reports of pain, aversion, and identification were collected in each trial.

Results Pain thresholds were higher in long-term meditators than in short-term meditators. In the short-term meditators, as compared to rest, pain was reduced in FAM and OMM, and aversion and identification in all meditation conditions. In the long-term meditators, pain was reduced only in LKM. Identification was reduced in the three forms of meditation, while aversion was not affected by meditation. Further analyses with a particular focus on long-term meditators showed that pain was predicted to increase with meditation expertise, aversion, and identification. Granger causality analysis revealed that aversion and pain, as well as aversion and identification, causally influenced each other; identification causally influenced pain. This pattern of results about the relationships between pain, aversion, and identification was largely overlapping in the group of short-term meditators.

Conclusions The findings reveal mechanisms of pain in interaction with aversive and identification mental states, as well as their modulation by meditation states and traits. They also suggest that pain feeling is the resultant of coupling of sensory and mental factors, thus highlighting the relevance of the second arrow of pain and providing a clarification of the epistemological gap between sensory causation and mental state causation of pain, in terms of a co-production mechanism with multiple stages. In particular, the evidence about the causal influences of identification on pain highlights a self-related factor of relevance in pain experiences that can be modulated by mindfulness. The study also inspires new testable neuroscientific hypotheses, and sheds new light on core Buddhist psychology models, based on evidence from a controlled experimental setting and experience dimension reports by long-term meditators with enhanced mindfulness skills.
\end{abstract}

Keywords Pain $\cdot$ Mindfulness $\cdot$ Meditation $\cdot$ Emotion $\cdot$ Self $\cdot$ Awareness

According to the Buddha's core teaching on the "two arrows of pain" in the Sallatha Sutta, pain experience is generally the resultant of both bodily and mental factors.

Valentina Nicolardi

valentinanicolardi@gmail.com

Antonino Raffone

antonino.raffone@uniroma1.it

Extended author information available on the last page of the article
In Nyanaponika Thera's (1998a) translation of the Sallatha Sutta, "When an untaught worldling is touched by a painful (bodily) feeling, he worries and grieves, he laments, beats his breast, weeps and is distraught. He thus experiences two kinds of feelings, a bodily and a mental feeling. It is as if a man were pierced by a dart and, following the first piercing, he is hit by a second dart." And then, with reference to a mentally well-trained disciple, "But in the case of a welltaught noble disciple, $\mathrm{O}$ monks, when he is touched by a 
painful feeling, he will not worry nor grieve and lament, he will not beat his breast and weep, nor will he be distraught. It is one kind of feeling he experiences, a bodily one, but not a mental feeling. It is as if a man were pierced by a dart, but was not hit by a second dart following the first one" (Nyanaponika Thera, 1998a).

This teaching, with other core teachings from the Buddha, has deeply influenced Buddhist insight meditation over almost 2,600 years (Goldstein, 2003), and, more recently, secular mindfulness-based interventions, such as in relating to feelings of distress and chronic pain (KabatZinn, 1995, 2010). In such Buddhist and secular mindfulness meditation practices, the role of mindfulness, i.e., the non-reactive and non-judgmental awareness of experience in the present moment (Baer et al., 2006; Bishop et al., 2004; Kabat-Zinn, 1995), is particularly emphasized. Indeed, mindfulness is assumed to play a key role in preventing the chaining of aversive emotional reactions and judgments on pain feelings, together with a calm mind induced by focusing and sustaining attention on a meditation object, such as the breath, and salutary attitudes such as acceptance and loving kindness toward pain experience and its causes and conditions. In the Buddhist philosophical and psychological tradition, these teachings have also been elaborated in refined treatises about consciousness, mental states, and the mechanisms of mental affliction and its release, in terms of Abhidhamma (Bhikkhu Bodhi, 2012; Nyanaponika Thera, 1998b) and Abhidharma (Conze, 1962; Thich Nhat Hanh, 2001).

A wide range of studies have shown that pain perception is influenced by cognitive and emotional states related to external events (Nicolardi et al., 2020; Rhudy \& Meagher, 2000; Valentini et al., 2017a, 2017b) and to the individual condition (Severeijns et al., 2001; Wiech \& Tracey, 2009). Such emotional states include experiential avoidance, suppression, reification, sensory-affective coupling, cognitive fusion, anticipatory worry, rumination, among others. The emotional states and individual conditions affecting pain may be related to the notion of the second arrow in Buddhist psychology. Given that pain has a strong affective and emotional dimension, as linked to avoidance and aversive states, and to the second arrow of pain in Buddhist psychology, the amygdala, and especially its central nucleus, has been included as a key component of the neural network typically involved in pain perception (Veinante et al., 2013). Based on neuroscientific and clinical evidence, Brewer and colleagues (Brewer et al., 2013a, 2013b) suggested a model of conditioning of human behavior and thought based on the Buddhist psychology model of (co)dependent origination. In this model, there is a key involvement of posterior cingulate cortex, a core hub of the default mode network of the brain, in a self-related associative memory. Such associative memory can also be related to identification with pain experience, as another core mental factor linked to the second arrow of pain according to Buddhist psychology.

Research on the neural correlates of meditation states and traits has shown that brain regions and networks implicated in pain experience and its emotional and cognitive modulation can be affected by mindfulness meditation. Two of the brain regions which seem most prominently involved in meditation states and traits, as well as in the emotional dimension of pain, are insular cortex and anterior cingulate cortex (Cahn \& Polich, 2006; Fox et al., 2016; Raffone et al., 2019; Tang et al., 2015). It has been shown that insular cortex and anterior cingulate cortex can be modulated by meditation states and traits (Zorn et al., 2020). Functional (Kral et al., 2018) and structural (Hölzel et al., 2011) neuroimaging have shown that the amygdala can be affected by mindfulness meditation training, plausibly in the direction of reduced reactivity and enhanced emotion regulation, thus also with potential implications for the regulation of the affective dimension of pain. Also, the mesolimbic dopamine system has been shown to be modulated by mindfulness meditation (Kirk \& Montague, 2015). Finally, Brewer and colleagues (Brewer et al., 2013a, 2013b) have addressed the influences of mindfulness meditation on the mechanism of self-involvement (identification) in a model related to the notion of (co)dependent origination in Buddhist psychology, and in particular on the role of posterior cingulate cortex, with a particular focus on craving in addiction. A similar mechanism can be involved in pain.

According to Buddhist psychology, mental events and processes are dynamically produced by interdependent causes and conditions in the mind, body, and environment, in terms of the fundamental teaching of (co)dependent origination or (co)dependent production (pațiccasamuppāda in Pāli; pratītyasamutpāda in Sanskrit) (Ajahn Amaro, 2017; Conze, 1953; Dunne, 2011a, 2011b; Harvey, 1993; Williams, 2002). According to this core Buddhist model of the temporal microstructure of the co-determined factors of mental activity depending on pre-stimulus mental states and dispositions, contact with a painful stimulus causes an unpleasant feeling tone, in the form of pain feeling. The arising pain feeling causes an aversive reaction, which in turn causes an impulse to avoid the contact, with a parallel self-involvement or identification with experience. The avoidance impulse with the concomitant identification with experience causes the enaction of the avoidance impulse in terms of a physical (e.g., increase of muscular tension or a movement) or mental action (e.g., a negative thought), such as for example the second arrow reactions described by the Buddha in the Sallatha Sutta reported above.

An essential feature of this model of the mind-body chain of reactivity is given by the circular influences of one factor not only on the next ones in the chain, but also on the ones arising earlier, both by changes after the action 
("resultants"), and by feedback to earlier factors, in a loop dynamics. This feature is in line with the neuroscientific understanding of recurrent interactions in brain systems for emotion (e.g., Salzman \& Fusi, 2010) and pain (e.g., Mano \& Seymour, 2015). In another fundamental teaching on the Four Noble Truths (e.g., Ajahn Sumedho, 1992), in the Second Noble Truth, the Buddha highlighted desire/aversion, arising after the feeling tone in the chain of reactivity in dependent origination, and the clinging/avoiding drive, occurring with a "fueling" of identification in dependent origination, as the two most important mental factors for causing distress and suffering. The influences of pain catastrophizing (Grant, 2014; Sullivan et al., 1995) could be understood and deconstructed in terms of such processes, including the influences of trait pain catastrophizing on sensory-affective coupling (Zorn et al., 2020).

The effects of meditation and mindfulness-based interventions on pain have increasingly become subject of psychological, neuroscientific, and clinical investigations (Gard et al., 2011; Hilton et al, 2016). It is generally assumed that meditation and mindfulness practitioners can develop the ability to experience the sensory-related aspect of pain (i.e., the "first arrow"), but to "let go" the evaluation of pain and aversive and identification reactions linked to it (i.e., the "second arrow") (Zeidan \& Vago, 2016). To date, scientific literature reported that meditation positively influences emotion and attention-related processes (Brefczynski-Lewis et al., 2007; Kasai et al., 2017; Nielsen \& Kaszniak, 2006), while its effect on pain is still debated (Hilton et al., 2016). Some studies found that mindfulness decreases reported pain (Bakhshani et al., 2016; Grossman et al., 2007; Schmidt et al., 2011), and increases pain acceptance in a sample of chronic pain patients (Morone et al., 2008). However, Hilton and colleagues (2016) conducted a meta-analysis and concluded that the effect of mindfulness on chronic pain is small and there is too much variability in the methodology used as well as in the collected measures to draw any conclusions.

Interestingly, a study based on a sample of mindfulness practitioners and healthy controls reported reduced pain unpleasantness and anticipatory anxiety in the practitioners but not in controls (Gard et al., 2011). This finding is also in line with previous studies showing a pain reduction in Zen practitioners as well as in Tibetan Buddhist practitioners (Grant et al., 2011; Lutz et al., 2013; Zeidan \& Vago, 2016). The authors concluded that mindfulness meditation has pain attenuating effects, which can be mediated by different mechanisms compared to those already reported in the study of pain modulation (Zeidan \& Vago, 2016). More specifically, they proposed that while a briefer meditative training engages cortico-thalamic-cortical interactions, which are able to reduce pain through inhibitory control or reappraisal, in long-term meditation practitioners pain reduction was found to be independent of opioid release and associated with greater activation in somatosensory regions and deactivation in areas related to appraisal (Zeidan \& Vago, 2016).

Gard and colleagues (2011) suggested that the nonjudgmental and accepting attitude linked to mindfulness, together with the concomitant attentional focus on the sensory aspects, could explain the pattern of brain activation they found in mindfulness practitioners. This is also in line with the evidence regarding neuroplastic changes in the structure and function of brain regions involved in the regulation of attention, emotion, and self-awareness related to mindfulness meditation (Malinowski, 2013; Raffone \& Srinivasan, 2009; Tang et al., 2015). Mindfulness meditation might implicate a top-down modulation of brain activities associated with pain, as related to the mechanisms highlighted by Wiech and colleagues (Wiech et al., 2008), who proposed that a descending pain modulation is triggered by lateral prefrontal cortex activity, which, by the activation of the rostral anterior cingulate cortex, induces a decreased activation of brain regions involved in pain.

In psychological, neuroscientific, and clinical research, meditation practices have been usefully classified into two main forms or styles-focused attention meditation (FAM) and open monitoring meditation (OMM) — depending on how attentional and monitoring processes are set (Cahn \& Polich, 2006; Lutz et al., 2008a; but see Travis \& Shear, 2010, for a different perspective)._Together with FAM and OMM, compassion meditation (CM) and loving kindness meditation (LKM) are two other important related forms of Buddhist meditation which have also inspired relevant secular developments and applications (Buddharakkhita, 1995; Hofmann et al., 2011; Lippelt et al., 2014; The Dalai Lama, 2001). CM focuses awareness upon a mental state of compassion, with sympathetic feelings and the aspiration to alleviate suffering of all living beings, including oneself; LKM upon a mental state of acceptance, friendliness, and concern for well-being and happiness of all living beings, including oneself. CM and LKM share attributes with both FAM and OMM, and are often practiced in synergy with FAM and OMM for the reduction of unwholesome mental states (e.g., anger, hatred) and for the development of virtues (Buddharakkhita, 1995; Hofmann et al., 2011; The Dalai Lama, 2001).

Given the different processes and mechanisms implicated in these different forms of meditation (Raffone et al., 2019; Yordanova et al., 2020), it appears relevant to understand their potentially different modulations of pain experiences. Perlman et al. (2010) compared the effects of FAM and OMM on self-reported pain unpleasantness and intensity in long-term meditators and novices. Long-term meditators, compared to novices, had a significant reduction of selfreported unpleasantness, but not intensity, of painful stimuli while practicing OMM, while no significant effects were found for FAM. LKM has been shown to attenuate chronic 
low back pain (Carlson \& Garland, 2005). Other studies have shown how different meditative states can differentially modulate the subjective experience of pain (Bakhshani et al., 2016; Grossman et al., 2007; Schmidt et al., 2011). However, to our knowledge, a systematic investigation of the modulation of pain experience by FAM, OMM, and LKM is still lacking.

Meditation expertise (experience) is crucially involved in pain modulation. In their recent functional magnetic resonance imaging (fMRI)-based review, Zeidan and colleagues (Zeidan et al., 2019) have delineated evidence from a range of fMRI studies showing that the neural mechanisms supporting mindfulness-induced pain attenuation differ across varying levels of meditation expertise. Zeidan and colleagues have also described recent investigations finding that higher levels of dispositional mindfulness in meditationnaïve individuals are associated with lower pain and greater deactivation of the posterior cingulate cortex, a key hub of the default mode network of the brain implicated in selfreferential processes. The latter finding also highlights the potential relevance of identification with pain experience, in "sensory-affective-self coupling," and its modulation by meditation practice.

Based on the assumption that the pain feeling is the resultant of both sensory (first arrow) and mental factors (second arrow), in this study, we aimed to characterize the effects of three different forms of meditation on pain experience by collecting three aspects of subjective experience: pain, aversion toward and identification with the painful experience. We hypothesized a modulation of pain experience by the three forms of meditation (FAM, OMM, LKM), with a particular emphasis on LKM, as this form of meditation is assumed to lead to a reduction of aversive states which are likely to intensify pain feelings. We also hypothesized that the three forms of meditation modulate aversion and identification, with a more pronounced modulation by LKM as related to a modulation of aversion in this form of meditation. Furthermore, we hypothesized that aversion and identification states predict or cause a higher pain experience, in line with Buddhist psychology models. To this aim, we collected subjective reports of pain, aversion and identification induced by brief painful electrical pulses while participants were engaged in different meditative conditions, or in a non-meditative rest condition. We tested the effects on such subjective reports of FAM, OMM, and LKM as compared with a resting state in a sample of expert or longterm meditators, i.e., Buddhist monks from the Theravada Buddhist tradition, and controls, i.e., short-term meditators. The effects of meditation expertise on pain experience in the long-term meditators were also assessed. Finally, to assess causal influences of aversion and identification time series on pain, and the reciprocal influences of pain on identification experiences, as well as the causal influences of aversion and identification on each other, we implemented Granger causality analysis (Granger, 1969).

\section{Methods}

\section{Participants}

Twelve monastics from the Theravada Buddhist tradition were included in the group of long-term meditators (3 females; mean age $=46 \pm 9.8$; with $17.92 \pm 12.19$ years of monastic life and practice). As suggested by the abbots of the monasteries, we could estimate thus an average of $120 \mathrm{~h}$ of practice per month during monastic life, with a balance of FAM, OMM, and LKM facets of meditation, for a total of $25,805 \pm 17,554 \mathrm{~h}$ of overall meditation practice to quantify meditation expertise. The group of short-term meditation practitioners included 12 participants with meditation experience ranging between 50 and $250 \mathrm{~h}$ (mean expertise $=130 \mathrm{~h}$ ) in secular mindfulness and/or Buddhist traditions emphasizing FAM, OMM, and LKM ( 6 females, mean age $=46 \pm 12$ ). Besides such meditation expertise, the short-term meditators further practiced with our instructions of FAM, OMM, and LKM for 10 days immediately before the study, $20 \mathrm{~min}$ per day for each form of meditation.

The highly experienced long-term meditators were monks and nuns residing at Amaravati Buddhist Monastery, in Southern England, and at Santacittarama Monastery, in Central Italy. Practices at both monasteries are aligned with the Thai Forest Theravada Buddhist tradition which is now established, widely acknowledged, and influential in the West. The long-term meditators practiced FAM (Samatha), OMM (Vipassana), and LKM (Metta) meditation forms in a balanced way in this tradition, often in integrated sessions, including silent meditation retreats (at least 3 months per year). In this tradition, the monks, nuns, and novice practitioners typically practice $2 \mathrm{~h}$ per day with the monastery community, with a regular intensification of practice during retreats, with several meditation sittings during the 3 months Winter retreat.

All participants had normal or corrected-to-normal vision and were naïve about the purpose of the experiment. None of the participants reported history of pain, or neurological or psychiatric disorders. Participants gave written, informed consent and were debriefed at the end of the experiment. All experimental procedures were approved by the ethics committee of "Sapienza," University of Rome, and were in accordance with the standards of the Declaration of Helsinki. 


\section{Procedure}

The painful electrical stimuli were pulses generated by a monophasic constant current stimulator (STIM140, H.T.L. srl, Amaro, UD, Italy). Stimuli were delivered through two surface electrodes of $6 \mathrm{~mm}$ of diameter $(\mathrm{Ag}-\mathrm{Cl}$, ElectroCap International, Inc. Eaton, Ohio) placed $5 \mathrm{~mm}$ from each other. Such a distance has been kept constant with a soft support to which the electrodes were affixed: it was attached to participant's hand through hypoallergenic surgical tape. The stimulation site was on the dorsal digital branch of the radial nerve, on the medial surface of the back of the left hand. The intensity range allowed by the instrument was between 2 and 50 milli Ampere (mA).

The whole experimental procedure consisted of three phases (Fig. 1): (1) determination of the absolute pain threshold, (2) stimulus intensity calibration, (3) task and stimulation blocks. During the threshold determination phase, the absolute pain threshold of each participant was determined. We considered the threshold as the minimum intensity of a stimulus that was perceived as painful. The threshold was determined by the ascending and descending method of limits (Nicolardi et al., 2020; Säterö et al., 2000; Valentini et al., 2017a, 2017b). During the calibration phase, instead, the participant was provided with supra-threshold electric stimuli delivered with a staircase procedure until the participant associated the same stimulus intensity with a moderate pain sensation $50 \pm 10 \%$ of times. The threshold and calibration phases allowed to select a moderately intense stimulus for each participant, to be used during the next stimulation blocks. We considered as moderately intense a stimulus rated between 30 and 50 on a $0-100$ numerical scale, based on previous research (Nicolardi et al., 2020; Valentini et al., 2017a, 2017b).

The third experimental phase consisted in a series of stimuli $(30 \times$ condition) delivered, as single events, during a non-meditative Rest condition, and during the three forms of meditation FAM, OMM, and LKM. The instructions for the four conditions, which were written together with the abbot of Amaravati Monastery, were as follows:

1. Rest: "Rest in a non-meditative relaxed state, without falling in sleep, while allowing any spontaneous thoughts and feelings to arise and unfold in the field of experience."

2. Focused attention (Samatha) meditation (FAM): "Sustain the focus of attention on breath sensations, such as at the nostrils, noticing readily and with acceptance any arising distraction, such as on thoughts or stimuli, and in case of detected distraction, return readily and gently to focus attention on the breath sensations."

3. Open monitoring (awareness) meditation (OMM): "With an open receptive awareness, observe the contents of experience as they arise, change and fade from moment to moment, without restrictions or judgments - such contents including breath and body sensations, sensations arising from contact with external stimuli, feelings and thoughts."

4. Loving kindness (Metta) meditation (LKM): "Generate and sustain metta, acceptance and friendliness towards yourself and the experience in the present moment, as well as towards any being, in any state or condition."

Ten practice trials were administered before the start of the experimental trials, in order to let participants to

A

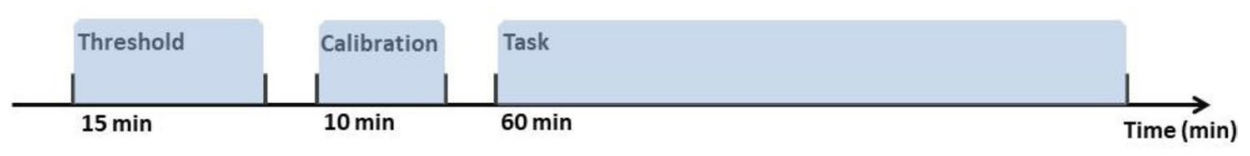

B

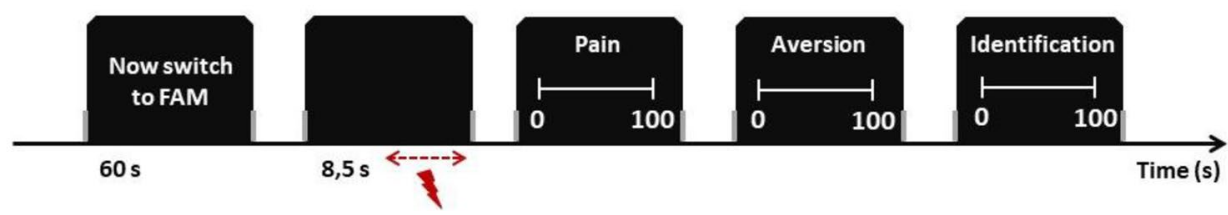

Fig. 1 Experimental procedure. B Single-trial details. After the measurement of the subjective pain threshold, participants underwent the calibration phase in order to find a moderate value to be used during the task. The task included a brief interval $(1 \mathrm{~m})$ to engage in the mindset of non-meditative Rest, or FAM, OMM, and LKM medita- tion forms, followed by a transient painful electrical stimulus delivered with a random interstimulus interval within a given interval (red-dotted line, bottom). Each stimulus was followed by three visual scales for ratings of pain, aversion and identification experiences 
familiarize with the three dimensions of experience to report. During the practice, participants tried a shorter version of the upcoming task; thus, they entered a meditative state, received a stimulus, and reported their ratings after it, up to ten stimuli. Further feedback was provided upon request for clarifications related to the meditation instructions and the dimensions of experience to report.

The switch to each condition (Rest, FAM, OMM, LKM) was delivered by means of an audio instruction following a triple beep signal, indicating that a change of condition was requested. After the audio instruction, the participant had $1 \mathrm{~min}$ to enter in the cued meditative or rest condition. Another sequence of three short beeps signaled the end of this 1-min period. The sequence of meditative conditions (Rest, FAM, OMM, LKM) was reiterated 3 times, for a total of 12 blocks of trials. Each block included 10 trials, for a total of 120 trials in the experiment. A brief break was provided between each block.

In each trial, the painful stimulus was delivered during the second half of an interval of $8500 \mathrm{~ms}$, with a random jitter between 4500 and $8500 \mathrm{~ms}$ (end of the interval). After each pain stimulus, participants had to rate three dimensions of experience related to the nociceptive stimulation in each trial: pain, in a single rating including both the intensity and the unpleasantness of the perceived stimulation; aversion or avoidance drive, and identification. The reports were collected in the following order: pain, aversion, and identification.

\section{Measures}

Before the beginning of the experimental blocks, pain threshold of each participant has been collected as single value, the energy value (mA) corresponding to the minimum intensity of a stimulus that was perceived as painful. Trial by trial, we also collected subjective reports of pain, as a single rating comprising both intensity and unpleasantness related to the nociceptive input; aversion, the drive to avoid or wanting to avoid the stimulus and the related experience; and identification, as the self-involvement or feeling the experience as "my pain" or "my feeling," or "getting caught up in the experience" (see also Brewer et al., 2013a, 2013b). The subjective reports were collected on a set of Visual Analogic Scales (VAS) ranging between 0 (no experience) and 100 (maximal experience). Each report was collected through a VAS that was presented on the screen until a response was given. To respond, participants should select the level of report by moving a grey bar (a cursor) toward the left or right by moving the mouse in the corresponding direction, and then clicking the left mouse button to confirm. Each time a response was given, the subsequent VAS was present. The trial ended after the identification report was collected. Finally, we collected information regarding the meditation practice of expert meditators as a single rating indicating the hours of meditative practice accumulated by each participant belonging to that group.

\section{Data Analyses}

\section{Linear Mixed Models}

Data analysis was performed by $R$, a free software programming language and software environment for statistical computing ( $R$ Development Core Team, 2014). Firstly, pain threshold collected at the beginning of the procedure was compared between long- and short-term meditators with a two-tailed $t$-test. Due to the high inter-individual variability of pain reports (Nielsen et al., 2005; Schultz et al., 2011), we opted to perform a linear mixed model (LMM or mixed-effects model, Pinheiro \& Bates, 2000) instead of the standard ANOVA. Indeed, mixed-effects models provide a flexible and powerful tool for the analysis of grouped data by incorporating random effects, or additional error terms, to account for correlation between observations within the same group (Pinheiro \& Bates, 2000). We conducted LMM analysis through the package lme4 Version 1.1-13 (Douglas et al., 2015).

We performed a Type III sums of square for ANOVA on a model where the fixed effects were the main effect of the condition (Rest, FAM, OMM, LKM) and group (long-term/ short-term meditators) respectively. The random part of the model included the factor condition and trials as random slope and the groups of participants as random intercept. We tested a separated model for each dependent variable: Pain (model 1), Aversion (model 2), and Identification (model 3). All the continuous variables have been mean-centered before conducting the analysis. In presence of significant results, post hoc tests were computed using the Tukey HSD test.

Three further models were tested on pain ratings, in which aversion (model 4), identification (model 5), and meditation expertise (model 6) were included as fixed effects as predictors of pain. These models have been tested on the long-term meditators only under the assumption of their enhanced introspective skills and accuracy due to intensive mental training. In particular, model 6 aimed to test the causal relation between meditation expertise and the experience of pain. Analyses involving the short-term meditators group are reported in Supplementary Materials.

\section{Granger Causality}

We performed Granger causality analysis in order to assess the causal influences of aversion and identification on pain, and the reciprocal causal influences of pain. To this aim, we 
considered the time sequence of identification, aversion, and pain ratings obtained from the sequence of trials as the time series to which apply the analysis.

For this analysis, we employed a Granger causality test by means of the R package VARs (Pfaff, 2008). Granger causality test (Granger, 1969) considers two time series ( $x$ and $y$ ) to assess if $x$ at different lags predicts $y$, while controlling for the causal effect of lagged $y$ on itself. For example, this method can be used to assess if the amount of a variable changing during time, e.g., the memory ability of an individual, is predicted by another variable, e.g., the attentional ability of the individual. The test is formulated against the null hypothesis that $x$ lags do not add predictive information to $y$ lags. To this aim, two regression models predicting $y$ are fitted: a first model including only the previous values of $y$, or $y$ lags, and a second one also including the previous values of $x$. The test compares the two models and thus assesses if the full model, i.e., the model including both $x$ and $y$ lags, is actually better in predicting $y$ than the partial model, i.e., the model including only the previous values of $y$. We conducted the Granger causality test comparing the two model by using the multivariate Rao's F-test (Rao, 1973). In the previous example, we could say that attention ability Granger-caused memory ability in time if the model containing both previous memory performance and attentional performance was better in predicting future memory performance than the model containing only the past memory performance.

Since our data variables were collected simultaneously, after assessing the causality in one direction, we had also to assess causality of $y$ on $x$ : Granger causality of $x$ on $y$ was assumed only if the previous values of $x$ predicted $y$, but not vice versa. If both causality directions were found to be significant, the two variables could have mutually influenced each other or a third latent confounder causing both $x$ and $y$ should have been considered or hypothesized. Moreover, since we conducted two tests, we applied Bonferroni's correction to the $p$ values (corrected alpha level $=0.025$ ). We also applied a wild bootstrap procedure to $p$ values to estimate their confidence intervals.

Before fitting the models and conducting the causality tests, we selected the optimal lag for the analysis. In our test, each trial was considered a lag, so at lag 1 , we assessed the effect that the value of $x$ in the previous trial had on the value of $y$ at the given trial, and at lag 2 we considered the value of $x$ two trials before, and so on. This preliminary analysis was conducted at a participant-based level; i.e., the time sequence of each participant was considered individually. Thus, we estimated the optimal lag from 1 to 10 out of 120 trials based on the individual data of each participant. The optimal lag was selected by considering four information criteria: Akaike (AIC), Hannan-Quinn (HQ), Schwarz (SC), and the forecast prediction error (FPE) (see Pfaff,
2008, for details). We selected the lag for which the criteria were optimal, i.e., the best fitted models. Then, we applied the chosen lag to the general time sequence of data as collected from all the assessed participants, in order to assess Granger causality overall in both the groups of long- and short-term meditators.

\section{Results}

\section{Pain Thresholds}

Firstly, $t$-test revealed a significant between-group difference on pain thresholds, with higher thresholds reported by the long-term meditators as compared to the short-term meditators ( $t=-4.3781 ; p<0.0002$; Fig. 2$)$.

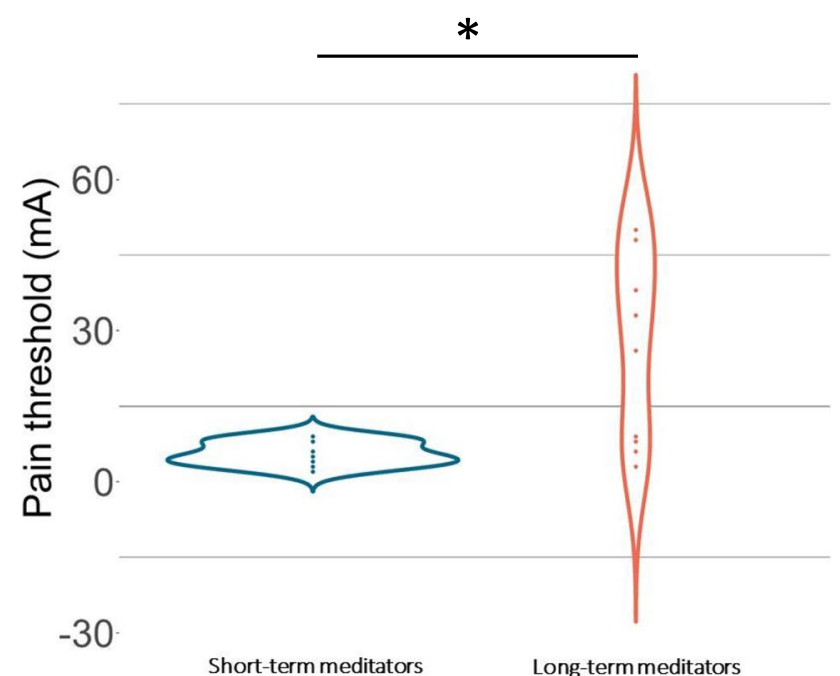

Fig. 2 Significant differences in pain thresholds between long- and short-term meditators. Violin plots show the distribution of the dependent variable Pain threshold, which is centered on the mean

Table 1 Analysis of deviance on pain ratings performed via a Type III Wald chi-square test. The bold lines indicate significant results. Tested model: Pain $\sim$ Condition $\times$ Group $+($ Condition + TriallSubj $)$

Analysis of deviance table (Type III Wald chi-square tests)

\begin{tabular}{lrcl}
\hline Response: Pain & Chisq & Df & $p$ value \\
\hline (Intercept) & 0.329 & 1 & 0.565 \\
Condition & $\mathbf{1 4 . 7 7 7}$ & $\mathbf{3}$ & $\mathbf{0 . 0 0 2} * *$ \\
Group & 0.557 & 1 & 0.455 \\
Condition: Group & $\mathbf{8 . 4 5 9}$ & $\mathbf{3}$ & $\mathbf{0 . 0 3 7}$ \\
\hline
\end{tabular}




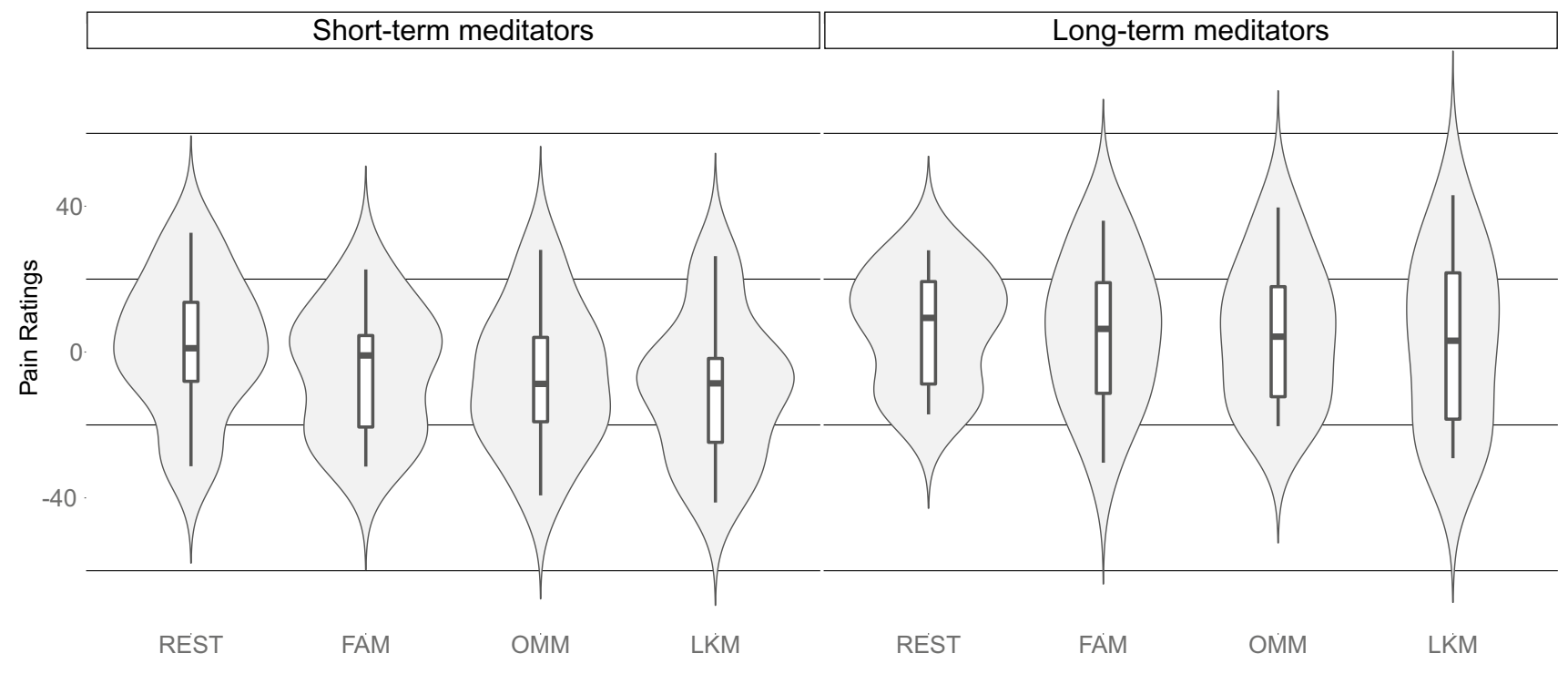

Fig. 3 Significant interaction between Condition ( $X$-axis) and Group (left panel: short-term meditators; right panel: long-term meditators) on pain ratings ( $Y$-axis). Violin plots show the distribution of the dependent variable Pain, which is centered on the mean. Each plot shows the distribution density of the mean by subject for each condi-

\section{Pain Subjective Ratings (Model 1)}

Pain experience showed a main effect of Condition $\left(\chi^{2}=14.772, p=0.002\right.$; Table 1$)$, and a significant interaction between Condition and Group $\left(\chi^{2}=8.459, p=0.037\right.$;

Table 2 Post hoc comparisons for the significant interaction between Condition and Group. Bold indicate significant comparisons. $p$-values were adjusted according to the Tukey method to compare a group of four estimates

Group: short-term meditators

\begin{tabular}{llllll}
\hline Contrast & Estimate & SE & df & t.ratio & $p$ value \\
\hline REST-FAM & 5.656 & 2.158 & 26.18 & 2.621 & 0.064 \\
REST-OMM & $\mathbf{7 . 1 0 3}$ & $\mathbf{2 . 2 6 0}$ & $\mathbf{2 6 . 1 8}$ & $\mathbf{3 . 1 4 2}$ & $\mathbf{0 . 0 2 0}$ \\
REST-LKM & $\mathbf{9 . 1 8 3}$ & $\mathbf{2 . 7 2 1}$ & $\mathbf{2 6 . 1 8}$ & $\mathbf{3 . 0 8 5}$ & $\mathbf{0 . 0 1 1}$ \\
FAM-OMM & 1.446 & 2.050 & 26.18 & 0.705 & 0.894 \\
FAM-LKM & 3.536 & 2.115 & 26.18 & 1.667 & 0.360 \\
OMM-LKM & 2.080 & 1.810 & 26.18 & 1.149 & 0.663 \\
Group: long-term meditators & & & & \\
Contrast & Estimate & SE & df & t.ratio & $p$ value \\
REST-FAM & -0.648 & 2.158 & 26.18 & -0.300 & 0.990 \\
REST-OMM & -1.081 & 2.260 & 26.18 & -0.478 & 0.963 \\
REST-LKM & 0.796 & 2.721 & 26.18 & 0.293 & 0.991 \\
FAM-OMM & 0.433 & 2.050 & 26.18 & -0.211 & 0.996 \\
FAM-LKM & 1.445 & 2.115 & 26.18 & 0.683 & 0.902 \\
OMM-LKM & 1.878 & 1.810 & 26.18 & 1.149 & 0.729 \\
\hline
\end{tabular}

tion. The central boxplot indicates the mean and standard deviation. The results show a significant pain decrease in LKM and OMM as compared to Rest only in the short-term meditators (left panel), while in the group of long-term meditators there were no significant differences between the conditions (right panel)

Fig. 3). Post hoc tests revealed a significant effect of OMM and LKM conditions compared to Rest, showing a pain reduction in these two meditative conditions, but only in the short-term meditators (as shown in Fig. 3, left panel), while in long-term meditators none of the meditative conditions resulted significantly different from Rest (as shown in Fig. 3, right panel; see Table 2 for the statistical test reports).

\section{Aversion (Model 2)}

Results on aversion ratings showed a main effect of Condition on reported aversion $\left(\chi^{2}=32.659 ; p<0.001\right.$; Table 3$)$, and a significant interaction Condition by group as well $\left(\chi^{2}=10.657 ; p=0.013\right.$; Table 3; Fig. 4). Post hoc comparisons for the main effect of Condition showed a significant

Table 3 Analysis of deviance on ratings of aversion performed via a Type III Wald chi-square test. The bold lines indicate significant results. Tested model: Aversion $\sim$ Condition $\times$ Group $+($ Condition + Trial $\mid S u b j)$

Analysis of deviance table (Type III Wald chi-square tests)

\begin{tabular}{lrll}
\hline Response: Aversion & \multicolumn{1}{c}{ Chisq } & Df & $p$ value \\
\hline (Intercept) & 0.804 & 1 & 0.369 \\
Condition & $\mathbf{3 2 . 6 5 9}$ & $\mathbf{3}$ & $\mathbf{3 . 8 e - 0 7 * * *}$ \\
Group & 0.010 & 1 & 0.917 \\
Condition: Group & $\mathbf{1 0 . 6 5 7}$ & $\mathbf{3}$ & $\mathbf{0 . 0 1 3}$
\end{tabular}




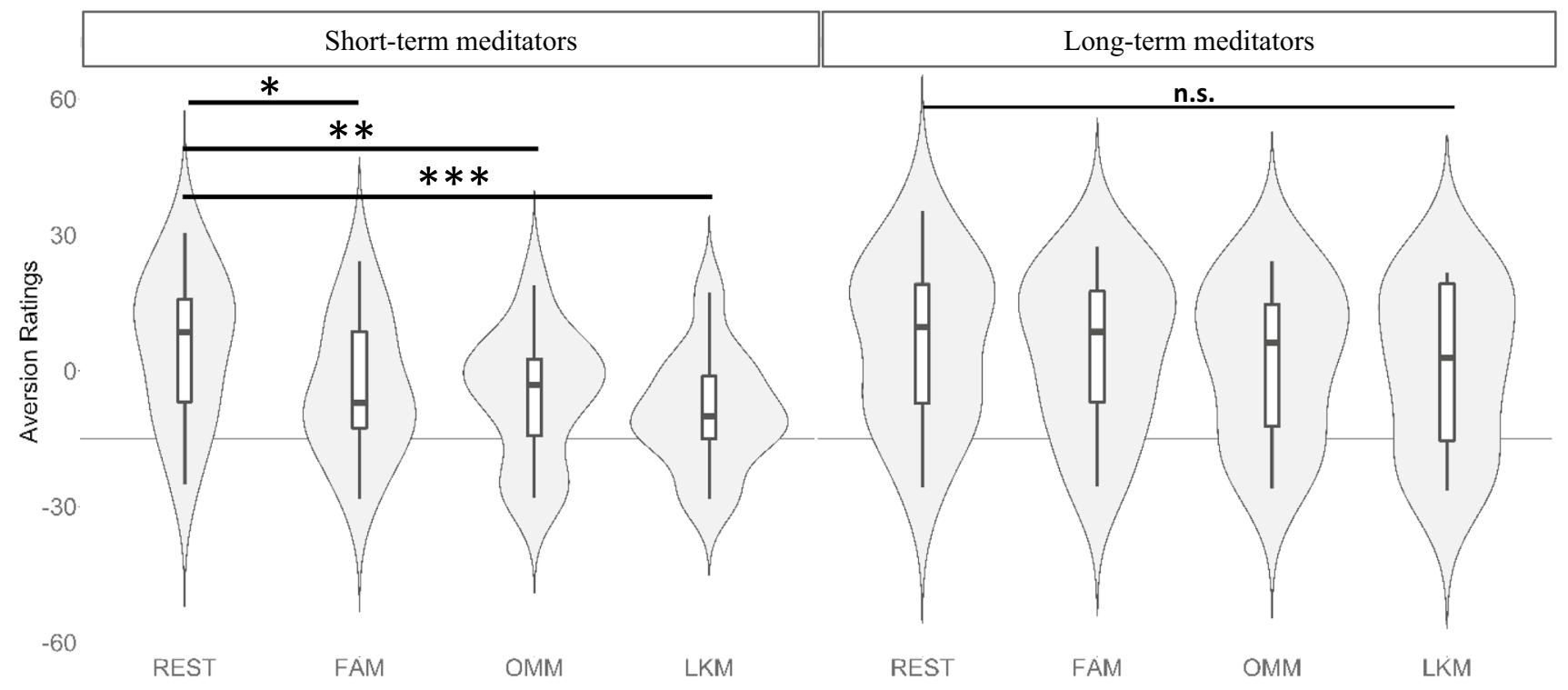

Fig. 4 Significant interaction between Condition ( $X$-axis) and Group on aversion ratings ( $Y$-axis). Violin plots show the distribution of the dependent variable Aversion, which is centered on the mean. Each plot shows the distribution density of the mean by subject for each condition. The central boxplot indicates the mean and standard devia-

Table 4 Post hoc comparisons for the significant interaction between Condition and Group. Bold indicate significant differences. $p$-values were adjusted according to the Tukey method to compare a group of four estimates

\begin{tabular}{llllll}
\hline Group: short-term meditators & & & & \\
\hline Contrast & Estimate & SE & Df & t.ratio & $p$ value \\
\hline REST-FAM & $\mathbf{8 . 8 0 1}$ & $\mathbf{2 . 3 9 2}$ & $\mathbf{2 6 . 1 8}$ & $\mathbf{3 . 6 7 8}$ & $\mathbf{0 . 0 0 5 5}$ \\
REST-OMM & $\mathbf{9 . 9 7 6}$ & $\mathbf{2 . 1 2 8}$ & $\mathbf{2 5 . 1 9}$ & $\mathbf{4 . 6 8 7}$ & $\mathbf{0 . 0 0 0 5}$ \\
REST-LKM & $\mathbf{1 2 . 9 9 8}$ & $\mathbf{2 . 6 0 7}$ & $\mathbf{2 5 . 7 5}$ & $\mathbf{4 . 9 8 5}$ & $\mathbf{0 . 0 0 0 2}$ \\
FAM-OMM & 1.174 & 1.267 & 23.60 & 0.927 & 0.7908 \\
FAM-LKM & 4.196 & 1.660 & 25.14 & 2.527 & 0.0798 \\
OMM-LKM & 3.022 & 1.591 & 26.11 & 1.899 & 0.2528 \\
Group: long-term meditators & & & & \\
Contrast & Estimate & SE & df & t.ratio & $p$ value \\
REST-FAM & 0.725 & 2.392 & 26.18 & 0.303 & 0.990 \\
REST-OMM & 1.440 & 2.128 & 25.19 & 0.677 & 0.904 \\
REST-LKM & 2.527 & 2.607 & 25.75 & 0.969 & 0.767 \\
FAM-OMM & 0.715 & 1.267 & 23.60 & 0.564 & 0.941 \\
FAM-LKM & 1.801 & 1.660 & 25.14 & 1.085 & 0.701 \\
OMM-LKM & 1.086 & 1.591 & 26.11 & 0.683 & 0.902 \\
\hline
\end{tabular}

difference between Rest and the three meditative conditions (Table 4). Post hoc comparisons for the interaction showed that the difference between Rest and each meditative condition was significant for the short-term meditators only, with reduced aversion in the three meditative conditions as compared to rest in the short-term meditators, tion. The results show a significant decrease of the aversion ratings for each meditative condition compared to Rest in the short-term meditators, while for the long-term meditators there were no significant differences

Table 5 Analysis of deviance on ratings of Aversion performed via a Type III Wald chi-square test on both groups. The bold lines indicate significant results. Tested model: Identification Condition $\times$ Group $+($ Condition + Trial $\mid$ Subj $)$

\begin{tabular}{lrcl}
\hline \multicolumn{4}{l}{ Analysis of deviance table (Type III Wald chi-square tests) } \\
\hline Response: identification & \multicolumn{1}{c}{ Chisq } & Df & $p$ value \\
\hline (Intercept) & 0.004 & 1 & 0.948 \\
Condition & $\mathbf{1 6 . 7 7 4}$ & $\mathbf{3}$ & $\mathbf{0 . 0 0 0 7 * * *}$ \\
Group & 0.126 & 1 & 0.722 \\
Condition: Group & 2.150 & 3 & 0.541 \\
\hline
\end{tabular}

while no significant difference was revealed for the longterm meditators.

\section{Identification (Model 3)}

A main effect of Condition $\left(\chi^{2}=16.774 ; p<0.0007\right.$; Table 5, Fig. 5) was found for Identification. Each meditation condition resulted significantly different from the Rest condition (Table 6). No significant difference between the two groups and no significant interaction have been reported between group and condition (group: $\chi^{2}=0.126 ; p=0.772$; interaction: $\left.\chi^{2}=2.150 ; p=0.541\right)$. 


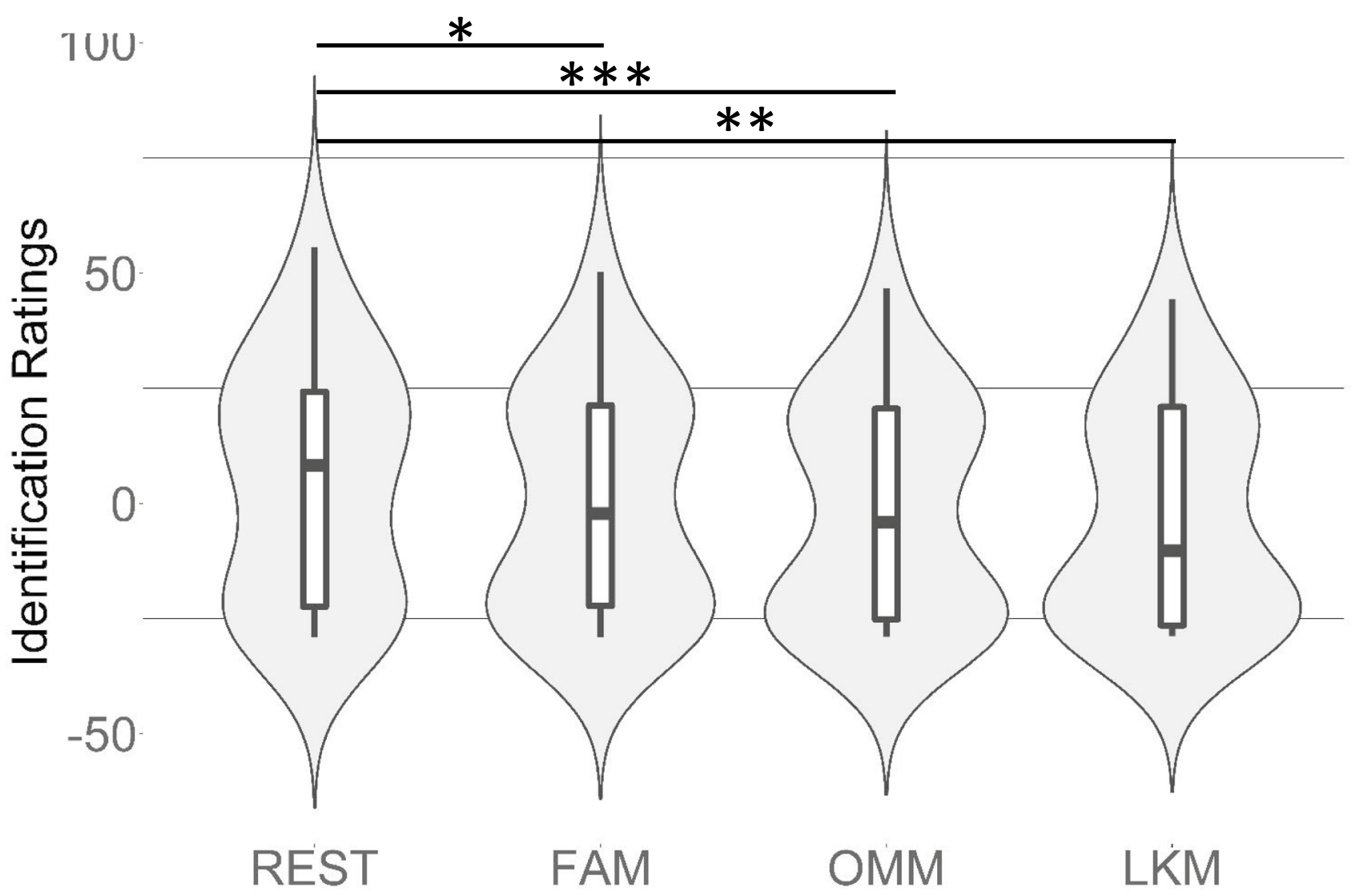

Fig. 5 Main effect of Condition ( $X$-axis) on ratings of Identification $(Y$-axis). Violin plots show the distribution of the dependent variable Identification, which is centered on the mean. Each plot shows the distribution density of the mean by subject for each condition. The central boxplot indicates the mean and standard deviation. The results show a significant decrease of identification for each meditative condition compared to Rest

Table 7 Analysis of deviance on ratings of aversion for the group of long-term meditators only performed via a Type III Wald chisquare test. The bold lines indicate significant results. Tested model: Pain Condition + Aversion (Condition + Trial |Subj)

Analysis of deviance table (Type III Wald chi-square tests)

\begin{tabular}{lccl}
\hline Response: Pain & Chisq & Df & $p$ value \\
\hline (Intercept) & 0.0001 & 1 & 0.990 \\
Condition & 0.839 & 3 & 0.840 \\
Aversion & $\mathbf{1 7 1 . 2 0 0}$ & $\mathbf{1}$ & $<\mathbf{2 e - 1 6 * * *}$ \\
\hline
\end{tabular}

6) as fixed effect regressors in the model other than the meditation condition. Model 4 showed a main effect of Aversion on positively predicting Pain; i.e., Pain significantly increased with Aversion $\left(\chi^{2}=307.155 ; p<0.0001\right.$; Table 7, Fig. 6). Model 5 also showed a main effect of Identification on positively predicting Pain; i.e., Pain significantly increased with Identification $\left(\chi^{2}=171.200\right.$; 


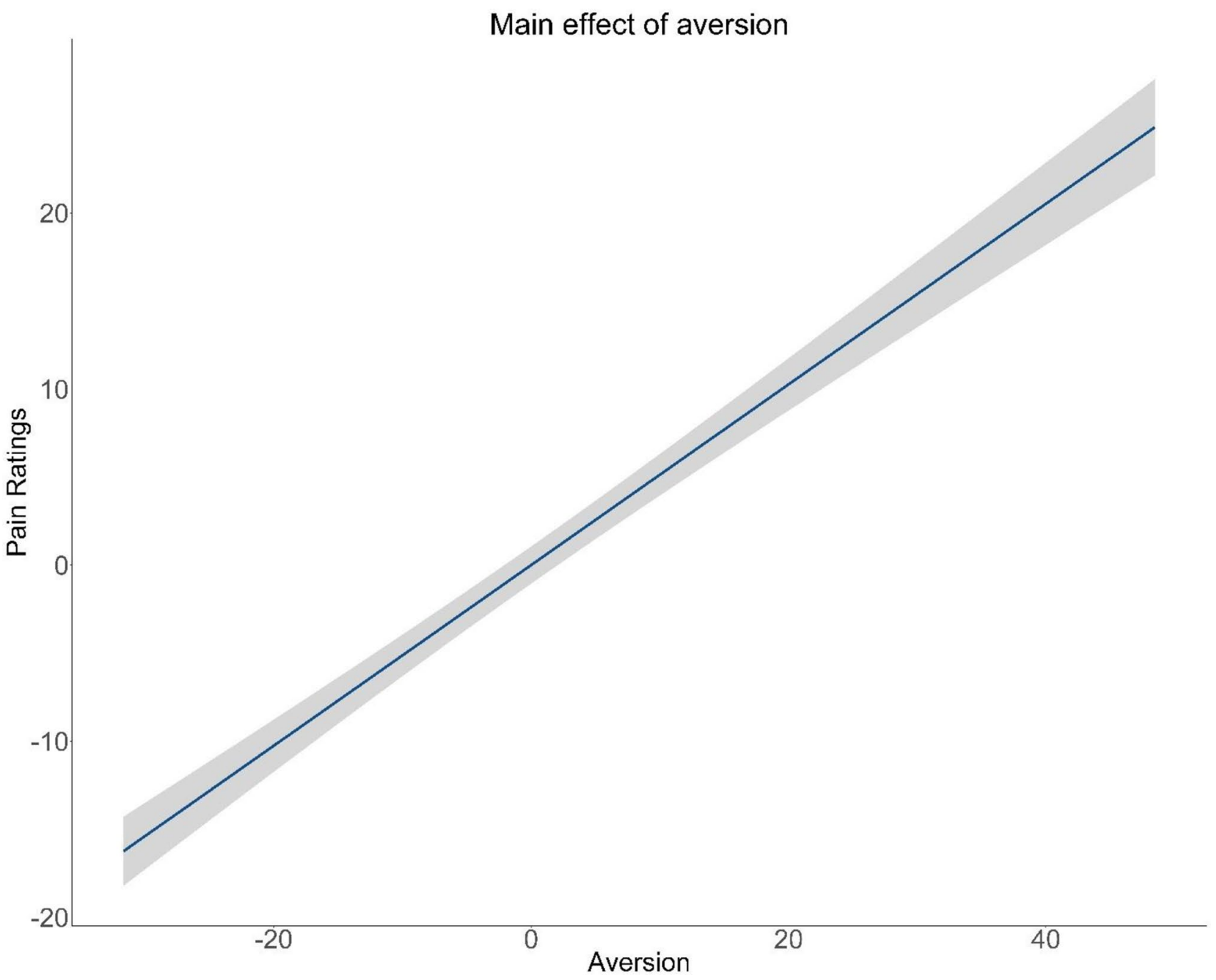

Fig. 6 The graph shows that Aversion was predictive of Pain, as reported by the long-term meditators on a trial-by-trial basis. Pain significantly increased with Aversion. The grey area around the line represents the standard error

Table 8 Analysis of deviance on ratings of identification for the group of long-term meditators only, performed via a Type III Wald chi-square test. The bold lines indicate significant results. Tested model: Pain Condition + Identification (Condition + Trial ISubj)

Analysis of deviance table (Type III Wald chi-square tests)

\begin{tabular}{lrll}
\hline Response: Pain & \multicolumn{1}{c}{ Chisq } & Df & $p$ value \\
\hline (Intercept) & 0.009 & 1 & 0.922 \\
Condition & 1.407 & 3 & 0.703 \\
Identification & $\mathbf{1 7 1 . 2 0 0}$ & $\mathbf{1}$ & $<\mathbf{2 e - 1 6 * * *}$ \\
\hline
\end{tabular}

$p<0.0001$; Table 8, Fig. 7). Finally, model 6 showed a main effect of meditation Condition and a main effect of meditation Expertise in predicting Pain $\left(\chi^{2}=2916.571\right.$; $p<0.0001$; Table 9, Fig. 8, and Fig. 9). The effect of Condition showed a significant pain reduction for LKM compared to Rest (Fig. 8), while pain significantly increased with Expertise (Fig. 9). Finally, we also conducted the same analyses with Aversion and Identification as predictors of Pain (models 4-5) on short-term meditators, as reported in Supplementary material. Also in the short-term meditators, we found that both Aversion and Identification positively predict pain (Table 10, ).

\section{Granger Causality Analysis}

We conducted Granger causality analysis on both long- and short-term meditators. About long-term meditators, we firstly selected the optimal lag for the analysis. Based on the information criteria indicated in the Data analysis section, the best lag was 1 , indicating that only the values of the previous trial should be considered in fitting the regression 
Fig. 7 The graph shows that Identification was predictive of Pain, as reported by the longterm meditators only on a trialby-trial basis. Pain significantly increased with Identification. The grey area around the line represents the standard error

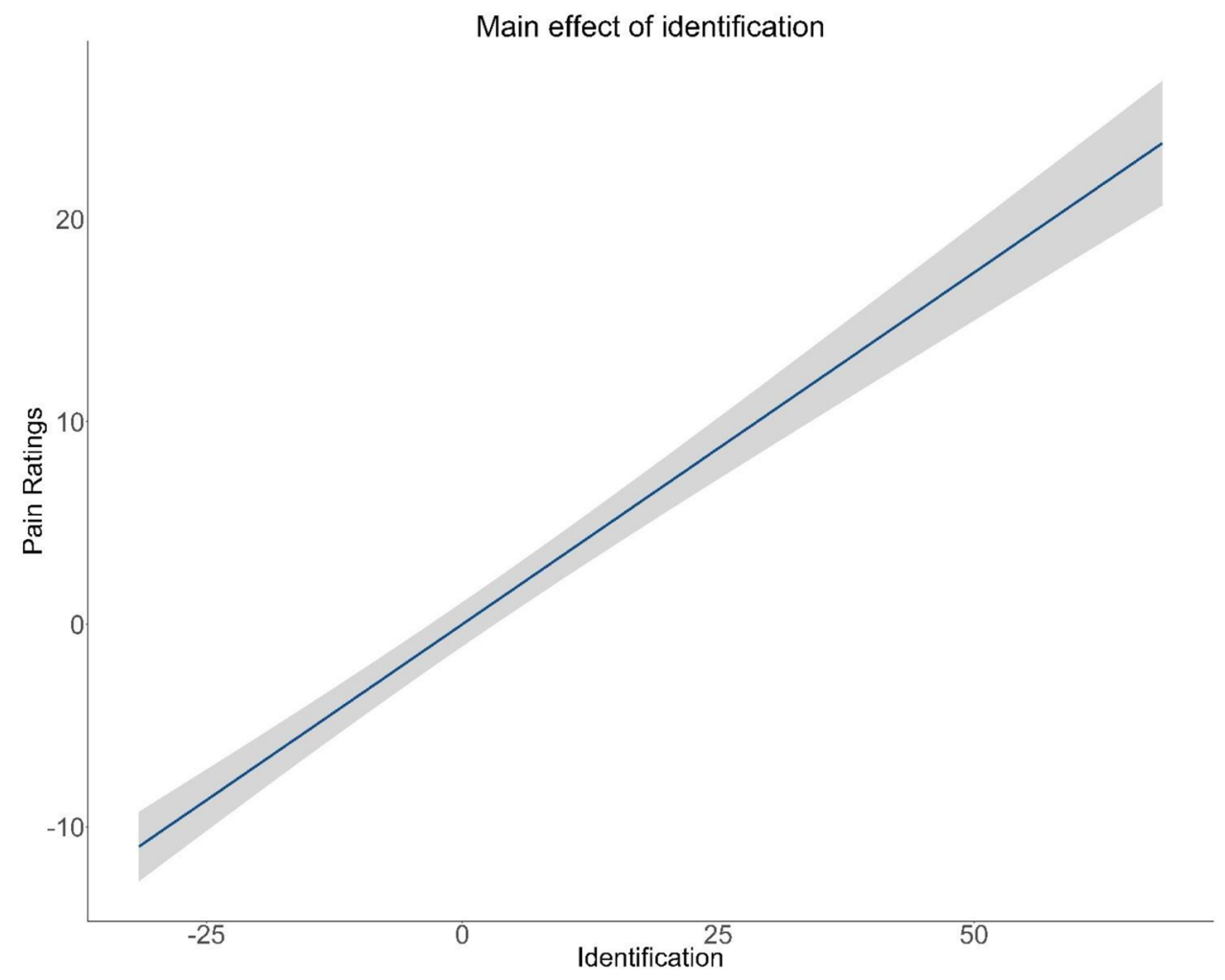

Table 9 Analysis of deviance on ratings of expertise for the group of long-term meditators only performed via a Type III Wald chisquare test. The bold lines indicate significant results. Tested model: Pain $\sim$ Condition + Expertise (1ISubj)

\begin{tabular}{lccc}
\hline \multicolumn{4}{l}{ Analysis of deviance table (Type III Wald chi-square tests) } \\
\hline Response: Pain & \multicolumn{1}{l}{ Chisq } & Df & $p$ value \\
\hline (Intercept) & $\mathbf{1 3 8 . 4 2 9}$ & $\mathbf{1}$ & $<\mathbf{2 . 2 e - 1 6 * * *}$ \\
Condition & $\mathbf{1 4 . 5 1 1}$ & $\mathbf{3}$ & $\mathbf{0 . 0 0 2 2 8 6}$ * $^{* *}$ \\
Expertise & $\mathbf{2 9 1 6 . 5 7 1}$ & $\mathbf{1 0}$ & $<\mathbf{2 . 2 e - 1 6 * * *}$ \\
\hline
\end{tabular}

models. Then, we tested the causal influences between Aversion and Pain.

We found that Aversion caused Pain, $F(1,1437)=5.01$, $p<0.01$, and that Pain caused Aversion, $F(1,1437)=11.45$, $p<0.01$. Second, we tested the causal influences between Aversion and Identification. We found that Aversion caused Identification, $F(1,1437)=40, p<0.01$, and that Identification caused Aversion, $F(1,1437)=79, p<0.01$. Third, we tested the causal influences between Identification and Pain. The test for Granger causality at lag 1 for Identification on Pain was significant, $F(1,1437)=18, p<0.01$, but the reverse test, i.e., Pain caused Identification, was not significant, $F(1,1437)=3.9, p=0.2$. Thus, in the long-term meditators, we found that aversion showed mutual influence with both pain and identification, whereas identification Grangercaused pain, i.e., the identification state in the previous trial predicted the pain experience at the next trial, in terms of causal influence.

We conducted the same analysis on short-term meditators. Again, the best lag was 1. About the causal influences between Aversion and Pain, we found that Aversion did not cause Pain, $F(1,1777)=0.01, p=0.96$, while Pain caused Aversion, $F(1,1777)=9.42, p<0.01$. About the causal influences between Aversion and Identification, we found that both Aversion caused Identification, $F(1,1777)=7.58, p<0.05$, and that Identification caused Aversion, $F(1,1777)=41.91, p<0.01$. Lastly, we tested the causal influences between Identification and Pain. Again, we found that both Identification caused Pain, $F(1$, $1777)=7.12, p<0.05$, and Pain caused Identification, $F(1$, $1777)=257.92, p<0.01$. To sum up, this analysis revealed that in the group of short-term meditators, pain Grangercaused aversion; i.e., the pain experienced in the previous trial predicted the aversion state in the next trial, while a mutual relationship existed between identification and aversion, and between pain and identification.

\section{Discussion}

In this study, we aimed to investigate the effects of three different forms of meditation on pain, aversion toward and identification with painful experience. Thus, we 
Fig. 8 Significant effect of Condition ( $X$-axis) on pain ratings ( $Y$-axis) in long-termmeditators. Violin plots show the distribution of the dependent variable Pain, which is centered on the mean. Each plot shows the distribution density of the mean by subject for each condition. The central boxplot indicates the mean and standard deviation. The results show a significant pain decrease in LKM compared to Rest

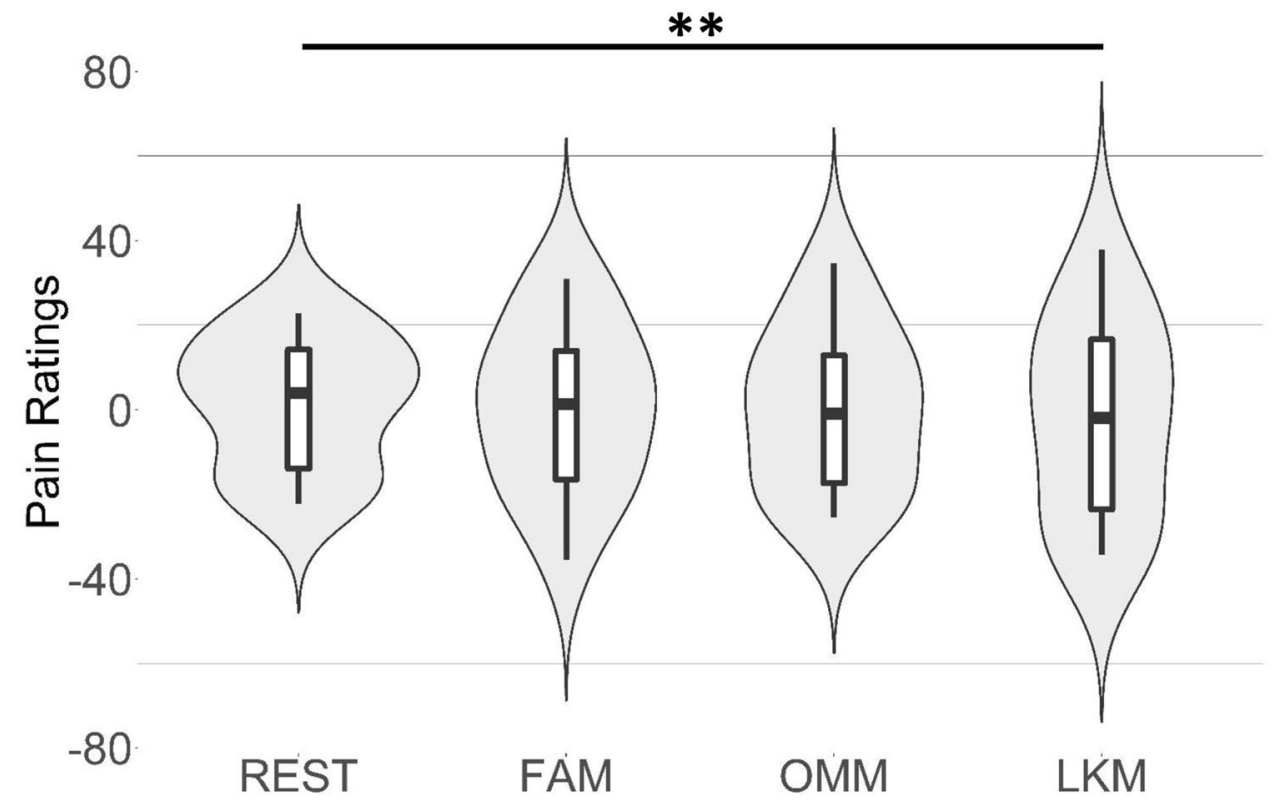

investigated the effects of FAM, OMM, and LKM on pain experience, as contrasted with a non-meditative rest condition, by involving both long- and short-term meditators. Moreover, with a particular focus on long-term meditators, by assuming their enhanced mindfulness of momentary mental states of aversion and identification related to pain experiences, on a trial-by-trial basis, we investigated (i) the effects of meditation expertise on pain experience, (ii) the effects of aversion and identification on pain experiences, and (iii) the causal influences of aversion and identification on pain, and the reciprocal influences of pain on identification experiences, as well as the causal influences of aversion and identification on each other, by means of Granger causality analysis.

\section{Effects of the Three Forms of Meditation in Long- and Short-Term Meditators}

Linear mixed model analysis revealed the effects of OMM and LKM on pain reduction, as contrasted to the nonmeditative Rest condition, only in the group of short-term meditators. This result was opposite to our hypothesis to find a stronger modulation by FAM in the short-term meditators, in light of evidence in the literature of FAM effects on pain experience after a few days of practice (Zeidan et al., 2011, 2015). As related to our study, Zorn and colleagues' (Zorn et al., 2020) results suggest that novices can also be successfully trained in OMM meditation and that this yields a different regulatory profile characterized by sensory-affective uncoupling, consistent with earlier work with expert practitioners (Perlman et al., 2010; see also Abdoun et al., 2019). Moreover, the hypothesis of a higher pain reduction in FAM was also supported by studies showing pain decrease when the attentional focus disengaged from pain due to a concomitant task, or due to a morally relevant event (Nicolardi et al., 2020; Valet et al., 2004; Van Damme et al., 2010). However, the electrical stimulation used to induce transiently pain in our study, with a moderate intensity, might have caused an attentional conflict in FAM between the intended meditation, focus on breath sensations, and the competing electrical stimulation. When used in the context of pain, FAM might involve components more akin to distraction, which has been linked to attentional gating mechanisms and overall pain reductions (Miron \& Duncan, 1989). During FAM, participants engage a narrowed attentional focus, in which the painful stimulus can be considered an interference for the meditative task which is to focus on the breath; instead, during OMM, participants keep a broader focus, by observing any contents of experience that arise.

This is also in line with the fact that most findings on meditation-based pain reduction focused on the reduction of the sensation of chronic pain (Hilton et al., 2016; Reiner et al., 2015), which is a long-lasting and persistent sensation, likely mitigated by the upcoming meditative practice. Instead, we used a short and phasic stimulus delivered while participants were meditating, thus creating a different scenario from an attentional perspective. Moreover, as it can be found in the literature about mismatching stimuli (Valentini et al., 2011; Zhao et al., 2015), the response to the deviant stimulus is enhanced when the stimuli are presented in different modalities. In parallel, during our experiment, participants were focused on their own breath (interoceptive input), while a concomitant but also extremely salient input arrived (somatosensory painful input). This might have boosted the 


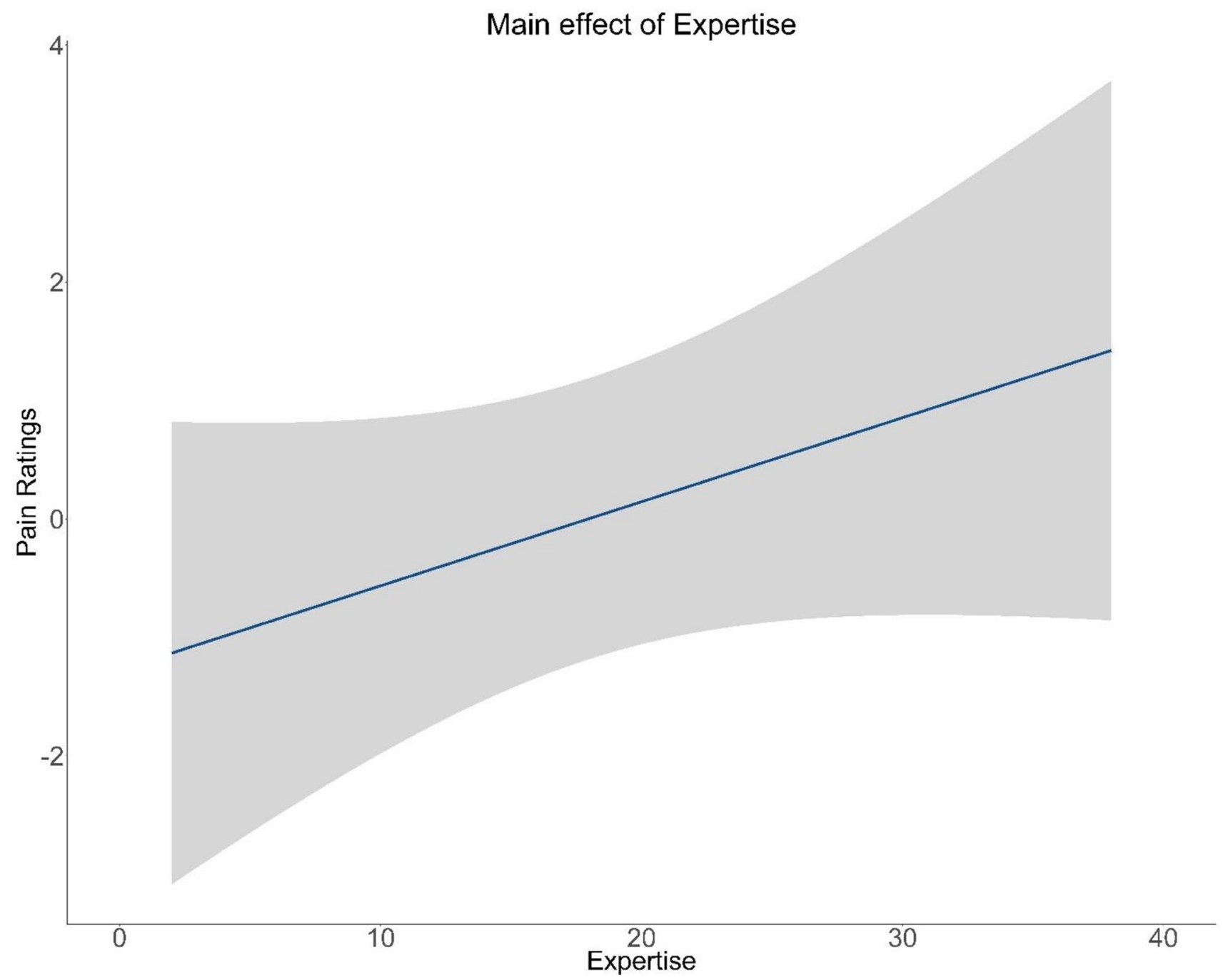

Fig. 9 The graph shows that meditation Expertise was predictive of Pain, as reported by the long-term meditators on a trial-by-trial basis. Pain significantly increased with Expertise, which is here measured in years. The grey area around the line represents the standard error

Table 10 Post hoc comparisons for the main effect of Condition (Rest, FAM, OMM, LKM) on Pain, considering only the group of long-term meditators. Bold indicates significant comparisons. $p$-values were adjusted according to the Tukey method to compare a group of four estimates

\begin{tabular}{llllll}
\hline Contrast & Estimate & SE & Df & $T$ ratio & $p$ value \\
\hline REST-FAM & 1.197 & 0.988 & 1440 & 1.212 & 0.619 \\
REST-OMM & 1.285 & 0.985 & 1440 & 1.305 & 0.560 \\
REST-LKM & $\mathbf{3 . 6 4 1}$ & $\mathbf{0 . 9 8 5}$ & $\mathbf{1 4 4 0}$ & $\mathbf{3 . 6 9 7}$ & $\mathbf{0 . 0 0 1}$ \\
FAM-OMM & 0.087 & 0.985 & 1440 & 0.088 & 0.999 \\
FAM-LKM & 2.443 & 0.985 & 1440 & 2.479 & 0.063 \\
OMM-LKM & 2.356 & 0.982 & 1440 & 2.399 & 0.077 \\
\hline
\end{tabular}

novelty and mismatching value of the painful input, increasing the pain feeling.
In the short-term meditators, pain reduction in OMM can be explained by an enhanced mindfulness during this form of meditation (e.g., Lutz et al., 2008a; Malinowski, 2013), leading to a reduced reactivity to pain, as particularly related to aversion and identification. Indeed, both aversion and identification were found to decrease in OMM as compared to the non-meditative rest condition in the short-term meditators. In the same group, the decrease of pain with LKM can be explained by increased emotional acceptance, opening, and friendliness toward experience in this form of meditation (Buddharakkhita, 1995; Hofmann et al., 2011; The Dalai Lama, 2001), which might have downregulated the mental reactivity related to pain. Indeed, both aversion and identification were found to be decreased in LKM in short-term meditators. Given that earlier studies reported a modulation of pain and its related neural responses by stimuli triggering a different emotional valence, in line with 
the reported effect of emotional valence on pain modulation (de Wied \& Verbaten, 2001; Rainville et al., 2005; Valentini et al., 2017a, 2017b), and the assumed positive valence of emotion with LKM, our finding could alternatively be explained in these terms. However, the emphasis on mental states of acceptance, opening, and friendliness in LKM, and the concomitant decreases in both aversion and identification, suggest that indeed such mental states might have led to the modulation of pain in LKM in the short-term meditators.

Against our expectations, linear mixed model analysis did not reveal pain modulation in the three forms of meditation in the long-term meditators. First of all, the different meditation expertise of participants in this group might have played a role, in line with other studies (see Tang et al., 2015, for a review with neuroscientific focus). Moreover, we collected a single rating for pain, without discriminating between intensity and unpleasantness, which may be considered a limitation of the study. Indeed, previous studies reported different modulations for intensity and unpleasantness ratings by different meditative states (Perlman et al., 2010), as well as a lack of differences on intensity but not on unpleasantness, between different groups of meditators (Gard et al., 2011). However, a further regression analysis revealed that also in the group of long-term meditators LKM reduced pain feelings, thus highlighting the potential of LKM for pain reduction across different stages of meditation practice and mental training (Kober et al., 2019).

Linear mixed model analysis also revealed that in the group of short-term meditators, but not in the long-term meditators, the mental state of aversion was reduced in the three forms of meditation as compared to rest. This result, with the further involvement of FAM in the reduction, mirrored the finding discussed above about pain scores. The finding in the group of short-term meditators suggests that the assumed mental states of attentional regulation and calmness enhanced in FAM, of non-reactive and non-judgmental awareness enhanced in OMM, and of acceptance, opening, and friendliness enhanced in LKM, all modulated the drive to avoidance induced by nociceptive stimulation. Against our expectations, however, in this analysis, the three forms of meditation did not modulate pain and aversion experiences in the long-term meditators.

The finding of a less activated mental state of identification across the conditions in the long-term meditators as compared to the short-term meditators suggests that reduction of self-involvement with intensive mental training may be a key regulator of emotional reactivity related to pain across meditative conditions, as also related to the notion of cognitive defusion (Masuda et al., 2004). Finally, it has to be noted that, together with the central role of meditation practice (in the FAM, OMM and LKM forms), also the emphasized wisdom and ethics, in light of the Eightfold Path (Ajahn Sumedho, 1992), play a crucial role in the mental training of the involved long-term meditators. Further studies may usefully assess the contributions of such core cultivations.

Regression analysis interestingly revealed that in the group of long-term meditators, meditation expertise negatively predicted pain across conditions. This finding can be explained by an increased capacity to let the pain feeling arise without suppressing it with increased meditation expertise, but plausibly without the second arrow influences related to aversion and identification, resembling the evidence about brain activations with stimuli related to pain of others, showing a more intense activation of the amygdala but with increased higher-level regulatory activities in anterior cingulate cortex and anterior insula (Lutz et al., 2008b). This account can be related to the neuroimaging (fMRI) study of Manna et al. (2010), with monks of the same tradition participating in this study, showing that reductions of activity in posterior insular cortex (insula) in FAM (as compared to non-meditative rest) negatively correlate with meditation expertise. Indeed, posterior insula is regarded as a key region related to pain feeling (Segerdahl et al., 2015), and was shown to be deeply deactivated in FAM by Manna et al. (2010). More expert meditators, though, can plausibly regulate the chain of reactivity related to nociceptive stimulation at later stages of emotional processing, beyond an anesthetic effect, although we also found that, on average, the group of long-term meditators showed a higher pain threshold as compared to the short-term meditators. The latter finding is in line with previous results reporting higher pain thresholds in expert meditators (Grant et al., 2009, 2010; Reiner et al., 2015). Moreover, this result, together with the effect of meditation expertise on pain, also suggest that long-term meditators could have a shifted baseline compared to naïve meditators.

\section{Relationships with the Models of the Two Arrows of Pain and Dependent Origination}

For these analyses, we assumed that there is a fundamental mechanism of interactivity between pain, aversion, and identification linked to the Buddhist psychology models of the two arrows and (co)dependent origination that does not differ between long- and short-term meditators. We thus focused in particular on the group of long-term meditators, by assuming their enhanced mindfulness of momentary mental states of aversion and identification related to pain experiences, on a trial-by-trial basis. Complementary analyses in the group of short-term meditators were anyway also performed.

Regression analyses on the group of long-term meditators sharply revealed that both mental states of aversion and identification are predictors of higher pain, in line with the model of the two arrows of pain and converging 
neuroscientific findings showing the modulation of pain by the brain mechanisms related to aversive states (Umberg \& Pothos, 2011; Veinante et al., 2013; Zeidan \& Vago, 2016) and self-involvement (Zeidan et al., 2019). In line with these results and theoretical insights, Granger causality analysis revealed that both mental states of aversion and identification have causal influences on pain feeling.

In agreement with our hypothesis based on the Buddhist psychology model of (co)dependent arising (Ajahn Amaro, 2017; Brewer et al., 2013a, 2013b; Conze, 1953; Dunne, 2011a, 2011b; Harvey, 1990; Williams, 2000) and converging neuroscientific insights, Granger analysis on the group of long-term meditators also revealed that pain feeling had a causal influence on aversion, and that in turn aversion had a causal influence on identification, according to the hypothesized chain of reactivity, or to the sequence of mental factors vedana (feeling tone), dosa (corresponding to aversion; with tanha corresponding to the other polarity of desire for this link), and upadana (identification) in the chain of co-dependent arising, in the Buddhist psychology model expressed in Pali terminology. Also, in agreement with our hypothesis, reciprocally, identification had a causal influence on pain feeling, besides its causal reciprocal influence on the next-neighbor link aversion. These causal influences are illustrated in Fig. 10.

Regression analyses on the group of short-term meditators revealed that both aversion and identification predict pain, thus matching the results on the group of long-term meditators. Granger analyses on the group of short-term meditators revealed causal influences overlapping with the group of long-term meditators: the causal influence of pain of aversion, the reciprocal causal influences between aversion and identification, and the causal influence of identification on pain. However, there was a mismatch in the Granger analyses on the two groups in respect to the influence of aversion on pain that was not significant in the group of short-term meditators, unlike in the group of long-term meditators, and to the influence of pain on identification that was not significant in the group of long-term meditators, unlike in the group of short-term meditators. The mismatches seem to highlight a relatively higher propensity of the short-term meditators to become aware of bottom-up influences of pain on both aversion and identification, and their relatively lower propensity to become aware of second arrow influences in terms of aversion on pain. Given that it is unlikely that aversion does not have influences on pain in short-term meditators, both in terms of Buddhist psychology models and affective neuroscience findings, we believe that long-term meditators might have been more accurate to reveal the pattern of causal influences between pain, aversion, and identification, due to their highly trained mindfulness of momentary feelings and mental states, although short-term meditators have remarkably revealed a subset of such core influences between such mental factors.

Our experimental findings with long-term meditators based on Granger causality analysis, also with some overlapping findings with short-term meditators, thus fall in line with the syntax of co-dependent arising in terms of reciprocal causality between next-neighbor links or arising mental factors, of potentially high interest in the field of Buddhist studies and the related secular field of mindfulness studies. Furthermore, the protentive or predictive causal influence of identification (upadana) on pain feeling highlights a loop interpretation or causally circular view of the links in the chain of mental reactivity, and emphasizes the causal roles that clinging or attachment (with a particular focus related to the self and the "wrong view," i.e., sakkaya-ditthi, about it) has at different stages of the chain of reactivity, before and

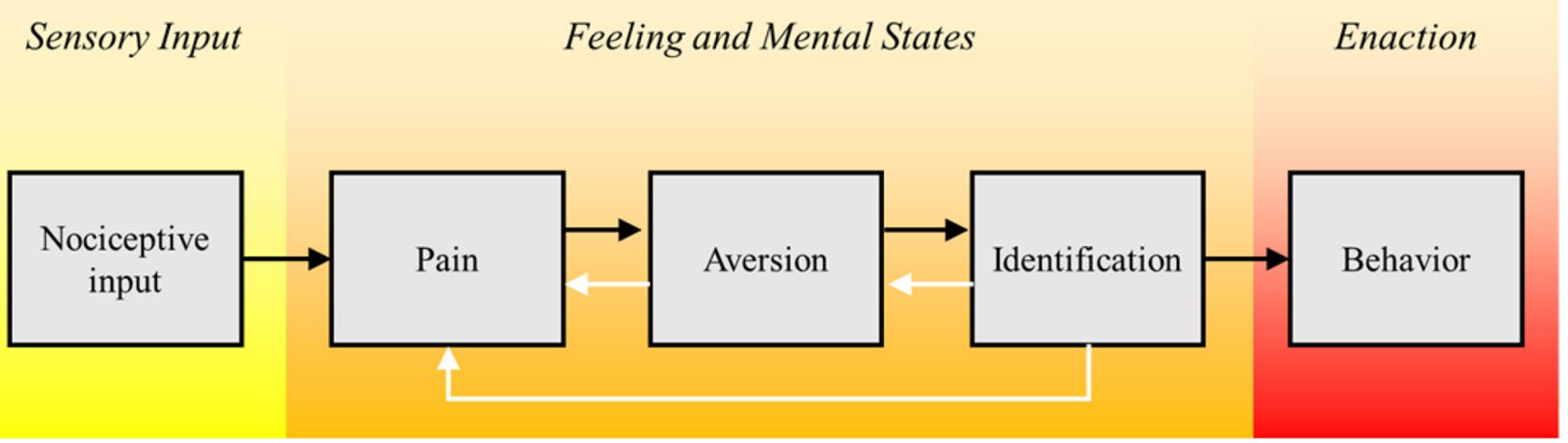

Fig. 10 Illustration of the stages implicated in the causation of pain feeling and the arising mental states of aversion and identification, starting from nociceptive input, and ending with behavior (enaction), related to the Buddhist psychology models of the two arrows of pain and (co)dependent origination. The rightward black arrows correspond to causal influences associated to the first arrow of pain, and the leftward white arrows to causal influences associated to the second arrow of pain. The diagram also characterizes pain feeling as the resultant of sensory, affective, and self-related factors, as indicated by the white arrows. Cognitive reappraisal may further act at a stage between identification and behavior 
after sensory input (contact, or phassa, in Pali). The latter finding also resonates with contemporary predictive coding models of pain perception (Fazeli \& Büchel, 2018; Song et al., 2019), showing that, together with bottom-up sensory input, top-down factors like pain expectations, which are based on the prediction error between previous expectations and the actual experience, contribute to update future predictions/expectations. Our findings are thus in line with this theoretical framework emphasizing top-down factors, such as expectations (Fazeli \& Büchel, 2018; Song et al., 2019), and self-related identification in our case, in affecting the upcoming experience.

The findings of our study related to the models of the two arrows of pain and co-dependent origination highlight the potential of mindfulness and loving kindness interventions for reducing aversion and identification with pain experience, which may have important implications for pain management (Carlson \& Garland, 2005; Hilton et al., 2017).

Besides the reduction of pain-related reactivity by attentional control and calmness by FAM practice, cognitive defusion or a reduced identification with pain experience as well as acceptance and friendliness toward pain experience, as cultivated in particular in OMM and LKM, can powerfully modulate pain experiences, including in chronic pain conditions (Hilton et al., 2017). Moreover, the reduction of mental states of aversion and identification could prevent secondary problems of anxiety and depression in chronic pain (Sheng et al., 2017; Woo, 2010). Thus, specific interventions based on mindfulness meditation, in FAM and OMM forms, as well as LKM, with a particular focus on monitoring aversive and identification mental states and counteracting them with the "antidotes" of acceptance, friendliness, and opening, could usefully be designed for an effective meditation-based management of chronic pain.

In particular, the evidence about the causal influences of identification on pain highlights a factor of relevance in pain experiences, which can be modulated by mindfulness. Indeed, a change in perspective on the self is one of the core domains of mindfulness training effectiveness (Hölzel et al., 2011), and can be related to a reduced or more flexible identification with experience. The modulation of such identification, together with cognitive reappraisal (Paoletti \& Ben-Soussan, 2020; Tracey, 2010), might significantly regulate the reactivity to pain after the stage of emotional (aversive) reactivity, thus affecting behavior.

More specifically, the loop or reciprocal causal influences between pain, aversion, and identification revealed by our study appear in line with the evidence of bidirectional influences between chronic pain and mental health conditions (Hooten, 2016). Indeed, it has been highlighted that besides depression, anxiety, and substance use disorders, chronic pain patients are at risk of other mental health problems, including cigarette smoking and suicide, and many of them have sustained sexual violence (Hooten, 2016). It can be hypothesized that interactive pain, aversion, and identification, as related to the Buddhist psychology models of the two arrows and (co)dependent origination, play a key role in such bidirectional influences. Clinical interventions integrating FAM, OMM, and LKM may thus be effective in the reduction of pain, aversion, and identification, as well as of their reciprocal influences. In particular, we suggest that the training of a sharper mindfulness of these mental factors and their mutual influences, which may include intensive meditation retreats, in combination with the cultivation of acceptance and loving kindness attitudes, can play a fundamental role in such interventions .

\section{Limitations and Future Research Directions}

Together with relatively small samples of short- and longterm meditators taking part in the study, another limitation of our investigation is that we collected pain ratings as a unified dimension, instead of discriminating between the dimensions of pain intensity and unpleasantness, as in other studies on pain and the effects of meditation on pain. This choice was due to the necessity to limit to three the dimensions to be reported in each trial; given our study focus, we considered both aversion and identification with the reported experience of pain as a single dimension. Further studies using our paradigm might shed light on the interactions between aversion and identification with both pain unpleasantness and intensity, as well as on the mutual causal influences between pain unpleasantness and intensity, taking also into account meditation expertise and the modulation by different forms of meditation. Another critical aspect of our sample is the gender unbalance in the LTM group, which included three female participants out of twelve; gender was instead balanced in the STM group. Further studies can usefully investigate the pattern of interactions between pain, aversion, and identification with cognitive reappraisal (Tracey, 2010), among other strategies of emotion regulation involved with pain (Paoletti \& Ben-Soussan, 2020).

Finally, a note of caution is needed about causal relationships revealed by Granger causality analysis as in our study. Indeed, causality as Granger causality is not necessarily true causality as it identifies the cause-effect relationships only with constant conjunctions (Maziusz, 2015). Indeed, one event following another does not imply causation, and third processes could influence such outcome. A thorough understanding of causal relationships between pain feeling (in terms of unpleasantness and intensity), aversion, and identification mental states would demand the experimental manipulation of conditions which are directly linked to such variables, and the measurement of the dependent changes in the other variables. For instance, pain could be manipulated 
through changes of the nociceptive stimulus intensity; aversion through a priming procedure and the use of negative (unpleasant) and highly activating images, such as inducing threat or disgust; and identification through instructing a meditative stance of defusion or disidentification with experience, as compared to a non-meditative rest condition and other meditation conditions which do not emphasize such meditative stance.

Our findings also inspire new neuroscientific hypotheses that can be tested in further neuroimaging investigations of brain functional connectivity in terms of Granger causality analysis (Seth et al., 2015). In particular, it can be hypothesized that, after nociceptive stimulation, posterior cingulate cortex, whose activation is plausibly associated with the mental state of identification or in getting caught up in one's experience (Brewer et al., 2013a, 2013b), is involved in mutual causal influences with aversion-related brain regions such as the amygdala (e.g., Veinante et al., 2013) and the striatum (Umberg \& Pothos, 2011). A previous magnetoencephalographic (MEG) investigation involving longterm meditators of the same tradition as in the present study (Marzetti et al., 2014) has interestingly shown that both FAM and OMM modulate oscillatory coupling of posterior cingulate cortex with a range of brain networks in the alpha band; this modulation may also be causally involved in the interplay of pain feeling and mental states of aversion and self-involvement. It is also interesting to note that posterior cingulate cortex has been associated with the dimension of catastrophizing in chronic pain (Lee et al., 2018), which may be related to identification with pain. Based on our findings, it can also be hypothesized that posterior cingulate cortex causally influences brain regions associated with pain feeling, such as (dorsal) posterior insula (Segerdahl et al., 2015), but without a reciprocal causal influence. Moreover, reciprocal causal influences between posterior insula and both amygdala and striatum related to aversive states, can be hypothesized. Finally, anterior insula can play a key role in integrating predictively identification-related states and pain feeling (Fazeli \& Büchel, 2018). The predicted functional connectivity appears also compatible with structural connectivity findings (Ghaziri et al., 2018; Khalsa et al., 2014; Kim et al., 2011).

Our findings, as related to the Buddhist psychology model of co-dependent origination, also suggest that time-resolved neuroimaging enabling a reliable source localization, such as MEG, would reveal different latencies of activity, which are related to the sources above, on a faster time scale of influences in the brain. Specifically, as related to an anticipatory (predictive) self-involvement, anterior insula would be activated first, followed by activations elicited by the nociceptive stimulation, with posterior insula related to pain feeling, then activation of amygdala and striatum related to aversiveness, then activation of posterior cingulate cortex related to the induced identification, with further waves of amplification in posterior insula related to the waves caused earlier in posterior cingulate cortex, amygdala, and striatum.

As also related to the general model of (co)dependent origination, common mechanisms involved in pain and addiction-related craving can be revealed, plausibly with a shared involvement of anterior insula (see also Naqvi et al., 2014) and posterior cingulate cortex (see also Brewer et al., 2013a, 2013b) as related to the identification or self-related clinging (attachment) dimension.

Finally, these neuroscientific hypotheses can be also tested in clinical studies, in which changes in causal influences between the mental factors of pain, aversion, and identification with the meditation-based clinical interventions are related to changes in causal influences in functional connectivity between brain regions and networks associated with such mental factors.

Supplementary Information The online version contains supplementary material available at https://doi.org/10.1007/s12671-021-01797-0.

Acknowledgements We would like to thank the monks and nuns of Amaravati and Santacittarama Buddhist Monasteries for their outstanding and extremely appreciated participation in our study. We are grateful to three anonymous reviewers for their sharp comments, remarks, and suggestions that have led to a substantially improved manuscript. We also thank the participants in the group of short-term meditators for their preparation for and participation in the experiment.

Author Contribution V. N. L. S., D. S., P. M., J. Y., V. K., S. M. A., and A. R. designed the study; V. N., L. S., D. S., and F. M. executed the study; V. N. and L. S. analyzed the data, and prepared the figures; V. N., L. S., D. S., S. M. A., and A. R. collaborated in the writing and editing of the final manuscript. All authors commented and reviewed the manuscript.

Funding This work has been supported by the grant from BIAL Foundation (Portugal) on the project "Aware Mind-Brain: bridging insights on the mechanisms and neural substrates of human awareness and meditation." A. R. has also been supported by the grant from Sapienza University of Rome on the project "Neurocognitive and molecular effects of mind-body practices: an integrated approach," number RG11715C7FE81576.

\section{Declarations}

Ethics Approval and Consent to Participate. Ethical approval for the study was obtained from the Ethics Review Committee of the Department of Psychology, "Sapienza" University of Rome, Italy (Reg. No. 23/18). The study was done in accordance with the national ethical standards. Informed written consent was taken from all participants before to start the experiment and they were debriefed at the end of the experiment.

Conflict of Interest The authors declare no competing interests.

Open Access This article is licensed under a Creative Commons Attribution 4.0 International License, which permits use, sharing, adaptation, distribution and reproduction in any medium or format, as long 
as you give appropriate credit to the original author(s) and the source, provide a link to the Creative Commons licence, and indicate if changes were made. The images or other third party material in this article are included in the article's Creative Commons licence, unless indicated otherwise in a credit line to the material. If material is not included in the article's Creative Commons licence and your intended use is not permitted by statutory regulation or exceeds the permitted use, you will need to obtain permission directly from the copyright holder. To view a copy of this licence, visit http://creativecommons.org/licenses/by/4.0/.

\section{References}

Abdoun, O., Zorn, J., Poletti, S., Fucci, E., \& Lutz, A. (2019). Training novice practitioners to reliably report their meditation experience using shared phenomenological dimensions. Consciousness and Cognition, 68, 57-72.

Amaro, A. (2017). The breakthrough. Amaravati Publications. Sumedho, A. (1992). The Four Noble Truths. Aruna Publications.

Baer, R. A., Smith, G. T., Hopkins, J., Krietemeyer, J., \& Toney, L. (2006). Using self-report assessment methods to explore facets of mindfulness. Assessment, 13(1), 27-45.

Bakhshani, N. M., Amirani, A., Amirifard, H., \& Shahrakipoor, M. (2016). The effectiveness of mindfulness-based stress reduction on perceived pain intensity and quality of life in patients with chronic headache. Global Journal of Health Science, 8, 47326.

Bates, D., Mächler, M., Bolker, B., \& Walker, S. (2014). Fitting linear mixed-effects models using lme4. arXiv preprint arXiv: 1406.5823

Bishop, S. R., Lau, M., Shapiro, S., Carlson, L., Anderson, N. D., Carmody, J., Segal, Z. V., Abbey, S., Speca, M., Velting, D., $\&$ Devins, G. (2004). Mindfulness: A proposed operational definition. Clinical Psychology: Science and Practice, 11, 230-241. https://doi.org/10.1093/clipsy.bph077

Bodhi, B. (2012). Comprehensive Manual of Abhidhamma: The Abhidhammattha Sangaha. Pariyatti Publishing.

Brefczynski-Lewis, J. A., Lutz, A., Schaefer, H. S., Levinson, D. B., \& Davidson, R. J. (2007). Neural correlates of attentional expertise in long-term meditation practitioners. Proceedings of the National Academy of Sciences, 104(27), 11483-11488.

Brewer, J. A., Davis, J. H., \& Goldstein, J. (2013a). Why is it so hard to pay attention, or is it? Mindfulness, the factors of awakening and reward-based learning. Mindfulness, 4(1), 75-80.

Brewer, J. A., Garrison, K. A., \& Whitfield-Gabrieli, S. (2013). What about the "self" is processed in the posterior cingulate cortex? Frontiers in Human Neuroscience, 7, 647.

Buddharakkhita, A. (1995). Karaniya Metta Sutta: The hymn of the universal love. Access to Insight: Readings in Theravada Buddhism.

Bushnell, M. C., Čeko, M., \& Low, L. A. (2013). Cognitive and emotional control of pain and its disruption in chronic pain. Nature Reviews Neuroscience, 14(7), 502-511.

Cahn, B. R., \& Polich, J. (2006). Meditation states and traits: EEG, ERP, and neuroimaging studies. Psychological Bulletin, 132(2), 180.

Carlson, L. E., \& Garland, S. N. (2005). Impact of mindfulnessbased stress reduction (MBSR) on sleep, mood, stress and fatigue symptoms in cancer outpatients. International Journal of Behavioral Medicine, 12(4), 278-285.

Conze, E. (1953). The ontology of the Prajñāpāramitā. Philosophy East and West, 117-129.

Conze, E. (1962). Buddhist Thought in India: Three Phases of Buddhist Philosophy. Routledge. de Wied, M., \& Verbaten, M. N. (2001). Affective pictures processing, attention, and pain tolerance. Pain, 90(1-2), 163-172.

The Dalai Lama. (2001). An open heart [Practicing Compassion in Everyday Life].

Dunne, J. (2011). Toward an understanding of non-dual mindfulness. Contemporary Buddhism, 12(1), 71-88.

Dunne, J. (2011). Madhyamaka in India and Tibet. In J. Garfield, W. Edelglass, Oxford Handbook of World Philosophy. Oxford University Press.

Fazeli, S., \& Büchel, C. (2018). Pain-related expectation and prediction error signals in the anterior insula are not related to aversiveness. Journal of Neuroscience, 38(29), 6461-6474.

Fox, K. C., Dixon, M. L., Nijeboer, S., Girn, M., Floman, J. L., Lifshitz, M., Ellamil, M., Sedlmeier, P., \& Christoff, K. (2016). Functional neuroanatomy of meditation: A review and metaanalysis of 78 functional neuroimaging investigations. Neuroscience \& Biobehavioral Reviews, 65, 208-228.

Fuchs, P. N., Peng, Y. B., Boyette-Davis, J. A., \& Uhelski, M. L. (2014). The anterior cingulate cortex and pain processing. Frontiers in Integrative Neuroscience, $8,35$.

Gard, T., Hölzel, B. K., Sack, A. T., Hempel, H., Lazar, S. W., Vaitl, D., \& Ott, U. (2011). Pain attenuation through mindfulness is associated with decreased cognitive control and increased sensory processing in the brain. Cerebral Cortex, 22(11), 2692-2702.

Ghaziri, J., Tucholka, A., Girard, G., Boucher, O., Houde, J. C., Descoteaux, M., Obaid, S., Gilbert, G., Rouleau, I., \& Nguyen, D. K. (2018). Subcortical structural connectivity of insular subregions. Scientific Reports, 8(1), 1-12.

Goldstein, J. (2003). Insight meditation: A psychology of freedom. Shambhala Publications.

Granger, C. W. J. (1969). Investigating causal relations by econometric models and cross-spectral methods. Econometrica, 37, 424-438.

Grant, J. A., \& Rainville, P. (2009). Pain sensitivity and analgesic effects of mindful states in Zen meditators: A cross-sectional study. Psychosomatic Medicine, 71, 106-114.

Grant, J. A., Courtemanche, J., Duerden, E. G., Duncan, G. H., \& Rainville, P. (2010). Cortical thickness and pain sensitivity in zen meditators. Emotion, 10(1), 43-53.

Grant, J. A. (2014). Meditative analgesia: The current state of the field. Annals of the New York Academy of Sciences, 1307(1), $55-63$.

Grossman, P., Tiefenthaler-Gilmer, U., Raysz, A., \& Kesper, U. (2007). Mindfulness training as an intervention for fibromyalgia: Evidence of postintervention and 3-year follow-up benefits in wellbeing. Psychotherapy and Psychosomatics, 76(4), 226.

Harvey, P. (1993). The mind-body relationship in Pāli Buddhism: A philosophical investigation. Asian Philosophy, 3(1), 29-41.

Harvey, P. (1995). An introduction to Buddhism. Cambridge University Press.

Hilton, L., Hempel, S., Ewing, B. A., Apaydin, E., Xenakis, L., Newberry, S., Colaiaco, B., Maher, A. R., Shanman, R. M., Sorbero, M. E., \& Maglione, M. A. (2016). Mindfulness meditation for chronic pain: Systematic review and meta-analysis. Annals of Behavioral Medicine, 51(2), 199-213.

Hofmann, S., Van Gessel, A. F. H., Verreycken, T., \& Bruggeman, P. (2011). Power dissipation, gas temperatures and electron densities of cold atmospheric pressure helium and argon RF plasma jets. Plasma Sources Science and Technology, 20(6), 065010.

Hölzel, B. K., Lazar, S. W., Gard, T., Schuman-Olivier, Z., Vago, D. R., \& Ott, U. (2011). How does mindfulness meditation work? Proposing mechanisms of action from a conceptual and neural perspective. Perspectives on Psychological Science, 6(6), 537-559. 
Hooten, W. M. (2016). Chronic pain and mental health disorders: Shared neural mechanisms, epidemiology, and treatment. Mayo Clinic Processing, 91(7), 955-970.

Kabat-Zinn, J. (1995). Mindfulness meditation. Nightingale-Conant Corporation.

Kabat-Zinn, J. (2010). Mindfulness meditation for pain relief: Guided practices for reclaiming your body and your life. Sounds True.

Kasai, Y., Sakakibara, T., Kyaw, T. A., Soe, Z. W., Han, Z. M., \& Htwe, M. M. (2017). Psychological effects of meditation at a Buddhist monastery in Myanmar. Journal of Mental Health, 26(1), 4-7.

Khalsa, S., Mayhew, S. D., Chechlacz, M., Bagary, M., \& Bagshaw, A. P. (2014). The structural and functional connectivity of the posterior cingulate cortex: Comparison between deterministic and probabilistic tractography for the investigation of structurefunction relationships. NeuroImage, 102, 118-127.

Kim, M. J., Loucks, R. A., Palmer, A. L., Brown, A. C., Solomon, K. M., Marchante, A. N., \& Whalen, P. J. (2011). The structural and functional connectivity of the amygdala: From normal emotion to pathological anxiety. Behavioural Brain Research, 223(2), 403-410.

Kirk, U., \& Montague, P. R. (2015). Mindfulness meditation modulates reward prediction errors in a passive conditioning task. Frontiers in Psychology, 6, 90.

Kober, H., Buhle, J., Weber, J., Ochsner, K. N., \& Wager, T. D. (2019). Let it be: Mindful acceptance down-regulates pain and negative emotion. Social Cognitive and Affective Neuroscience, 14(11), $1147-1158$.

Kral, T. R., Schuyler, B. S., Mumford, J. A., Rosenkranz, M. A., Lutz, A., \& Davidson, R. J. (2018). Impact of short-and long-term mindfulness meditation training on amygdala reactivity to emotional stimuli. NeuroImage, 181, 301-313.

Lee, D. J., Kulubya, E., Goldin, P., Goodarzi, A., \& Girgis, F. (2018). Review of the neural oscillations underlying meditation. Frontiers in Neuroscience, 12, 178.

Lippelt, D. P., Hommel, B., \& Colzato, L. S. (2014). Focused attention, open monitoring and loving kindness meditation: Effects on attention, conflict monitoring, and creativity-A review. Frontiers in Psychology, 5, 1083.

Lutz, A., Slagter, H. A., Dunne, J. D., \& Davidson, R. J. (2008). Attention regulation and monitoring in meditation. Trends in Cognitive Sciences, 12(4), 163-169.

Lutz, A., Brefczynski-Lewis, J., Johnstone, T., \& Davidson, R. J. (2008b). Regulation of the neural circuitry of emotion by compassion meditation: Effects of meditative expertise. PloS one, 3(3).

Malinowski, P. (2013). Neural mechanisms of attentional control in mindfulness meditation. Frontiers in Neuroscience, 7, 8.

Manna, A., Raffone, A., Perrucci, M. G., Nardo, D., Ferretti, A., Tartaro, A., Londei, A., Del Gratta, C., Olivetti Belardinelli, M., \& Romani, G. L. (2010). Neural correlates of focused attention and cognitive monitoring in meditation. Brain Research Bulletin, 82(1-2), 46-56.

Mano, H., \& Seymour, B. (2015). Pain: A distributed brain information network?. PLoS biology, 13(1).

Mariusz, M. (2015). "A review of the Granger-causality fallacy". The Journal of Philosophical Economics: Reflections on Economic and Social Issues. VIII. (2).

Marzetti, L., Di Lanzo, C., Zappasodi, F., Chella, F., Raffone, A., \& Pizzella, V. (2014). Magnetoencephalographic alpha band connectivity reveals differential default mode network interactions during focused attention and open monitoring meditation. Frontiers in Human Neuroscience, 8, 832.

Masuda, A., Hayes, S. C., Sackett, C. F., \& Twohig, M. P. (2004). Cognitive defusion and self-relevant negative thoughts: Examining the impact of a ninety year old technique. Behaviour Research and Therapy, 42(4), 477-485.
Morone, N. E., Greco, C. M., \& Weiner, D. K. (2008). Mindfulness meditation for the treatment of chronic low back pain in older adults: A randomized controlled pilot study. Pain, 134(3), 310-319.

Naqvi, N. H., Gaznick, N., Tranel, D., \& Bechara, A. (2014). The insula: A critical neural substrate for craving and drug seeking under conflict and risk. Annals of the New York Academy of Sciences, 1316, 53.

Nicolardi, V., Panasiti, M. S., D’Ippolito, M., Pecimo, G. L., \& Aglioti, S. M. (2020). Author Correction: Pain perception during social interactions is modulated by self-related and moral contextual cues. Scientific Reports, 10(1), 1-1.

Nielsen, C. S., Price, D. D., Vassend, O., Stubhaug, A., \& Harris, J. R. (2005). Characterizing individual differences in heat-pain sensitivity. Pain, 119, 65-74.

Nielsen, L., \& Kaszniak, A. W. (2006). Awareness of subtle emotional feelings: A comparison of long-term meditators and nonmeditators. Emotion, 6(3), 392.

Nyanaponika Thera (1998a). Sallatha Sutta: The Dart. (translated from the Pali). Buddhist Publication Society.

Nyanaponika Thera (1998b). Abhidhamma studies: Buddhist explorations of consciousness and time. Simon and Schuster.

Paoletti, P., \& Soussan, T. D. B. (2020). Reflections on silence and consciousness without contents according to the Sphere Model of Consciousness. Frontiers in Psychology.

Perlman, D. M., Salomons, T. V., Davidson, R. J., \& Lutz, A. (2010). Differential effects on pain intensity and unpleasantness of two meditation practices. Emotion, 10(1), 65.

Peyron, R., Laurent, B., \& Garcia-Larrea, L. (2000). Functional imaging of brain responses to pain. A review and metaanalysis. Neurophysiologie Clinique/Clinical Neurophysiology, 30(5), 263-288.

Pfaff, B. (2008). VAR, SVAR and SVEC models: Implementation within R Package vars. Journal of Statistical Software, 27(4).

Pinheiro, J. C., \& Bates, D. M. (2000). Linear mixed-effects models: Basic concepts and examples. Mixed-effects models in $S$ and S-Plus, 3-56.

R Core Team. (2014). R: a language and environment for statistical computing.

Raffone, A., \& Srinivasan, N. (2009). An adaptive workspace hypothesis about the neural correlates of consciousness: Insights from neuroscience and meditation studies. Progress in Brain Research, 176, 161-180.

Raffone, A., Marzetti, L., Del Gratta, C., Perrucci, M. G., Romani, G. L., \& Pizzella, V. (2019). Toward a brain theory of meditation. In Progress in brain research (Vol. 244, pp. 207-232). Elsevier.

Rainville, P., Bao, Q. V. H., \& Chrétien, P. (2005). Pain-related emotions modulate experimental pain perception and autonomic responses. Pain, 118(3), 306-318.

Rao, C. R. (1973). Linear statistical inference and its application (2nd ed.). Wiley.

Reiner, K., Granot, M., Soffer, E., \& Lipsitz, J. D. (2015). A brief mindfulness meditation training increases pain threshold and accelerates modulation of response to tonic pain in an experimental study. Pain Medicine, 17(4), 628-635.

Salzman, C. D., \& Fusi, S. (2010). Emotion, cognition, and mental state representation in amygdala and prefrontal cortex. Annual Review of Neuroscience, 33, 173-202.

Säterö, P., Klingenstierna, U., Karlsson, T., \& Olausson, B. (2000). Pain threshold measurements with cutaneous argon laser, comparing a forced choice and a method of limits. Progress in Neuro-Psychopharmacology and Biological Psychiatry, 24(3), 397-407.

Sayadaw, M. (2016). Manual of insight. Simon and Schuster. 
Schmidt, S., Grossman, P., Schwarzer, B., et al. (2011). Treating fibromyalgia with mindfulness-based stress reduction: Results from a 3-armed randomized controlled trial. Pain, 152, 361-369.

Schulz, E., Tiemann, L., Schuster, T., Gross, J., \& Ploner, M. (2011). Neurophysiological coding of traits and states in the perception of pain. Cerebral Cortex, 21(10), 2408-2414.

Segerdahl, A. R., Mezue, M., Okell, T. W., Farrar, J. T., \& Tracey, I. (2015). The dorsal posterior insula subserves a fundamental role in human pain. Nature Neuroscience, 18(4), 499-500.

Seth, A. K., Barrett, A. B., \& Barnett, L. (2015). Granger causality analysis in neuroscience and neuroimaging. Journal of Neuroscience, 35(8), 3293-3297.

Severeijns, R., Vlaeyen, J. W., van den Hout, M. A., \& Weber, W. E. (2001). Pain catastrophizing predicts pain intensity, disability, and psychological distress independent of the level of physical impairment. The Clinical Journal of Pain, 17(2), 165-172.

Sheng, J., Liu, S., Wang, Y., Cui, R., \& Zhang, X. (2017). The link between depression and chronic pain: Neural mechanisms in the brain. Neural Plasticity, 2017.

Song, Y., Kemprecos, H., Wang, J., \& Chen, Z. (2019, July). A predictive coding model for evoked and spontaneous pain perception. In 201941 st Annual International Conference of the IEEE Engineering in Medicine and Biology Society (EMBC) (pp. 2964-2967)

IEEE.Starr, C. J., Sawaki, L., Wittenberg, G. F., Burdette, J. H., Oshiro, Y., Quevedo, A. S., \& Coghill, R. C. (2009). Roles of the insular cortex in the modulation of pain: insights from brain lesions. Journal of Neuroscience, 29(9), 2684-2694

Sullivan, M. J. L., Bishop, S. R., \& Pivik, J. (1995). The pain catastrophizing scale: Development and validation. Psychological Assessment, 7(4), 524-532.

Surawy, C., McManus, F., Muse, K., \& Williams, J. M. G. (2015). Mindfulness-based cognitive therapy (MBCT) for health anxiety (hypochondriasis): Rationale, implementation and case illustration. Mindfulness, 6(2), 382-392.

Tang, Y. Y., Hölzel, B. K., \& Posner, M. I. (2015). The neuroscience of mindfulness meditation. Nature Reviews Neuroscience, 16(4), 213-225.

Thich Nhat Hanh. (2001). Transformation at the base: Fifty verses on the nature of consciousness. Parallax Press.

Torta, D. M., Legrain, V., Mouraux, A., \& Valentini, E. (2017). Attention to pain! A neurocognitive perspective on attentional modulation of pain in neuroimaging studies. Cortex, 89, 120-134.

Tracey, I. (2010). Getting the pain you expect: Mechanisms of placebo, nocebo and reappraisal effects in humans. Nature Medicine, 16(11), 1277-1283.

Travis, F., \& Shear, J. (2010). Focused attention, open monitoring and automatic self-transcending: Categories to organize meditations from Vedic, Buddhist and Chinese traditions. Consciousness and Cognition, 19(4), 1110-1118.

Umberg, E. N., \& Pothos, E. N. (2011). Neurobiology of aversive states. Physiology \& Behavior, 104(1), 69-75.

Valentini, E., Nicolardi, V., \& Aglioti, S. M. (2017a). Visual reminders of death enhance nociceptive-related cortical responses and event-related alpha desynchronisation. Biological Psychology, $129,121-130$.
Valentini, E., Nicolardi, V., \& Aglioti, S. M. (2017). Painful engrams: Oscillatory correlates of working memory for phasic nociceptive laser stimuli. Brain and cognition, 115, 21-32.

Valet, M., Sprenger, T., Boecker, H., Willoch, F., Rummeny, E., Conrad, B., Erhard, P., \& Tolle, T. R. (2004). Distraction modulates connectivity of the cingulo-frontal cortex and the midbrain during pain-An fMRI analysis. Pain, 109(3), 399-408.

Van Damme, S., Legrain, V., Vogt, J., \& Crombez, G. (2010). Keeping pain in mind: A motivational account of attention to pain. Neuroscience \& Biobehavioral Reviews, 34(2), 204-213.

Veinante, P., Yalcin, I., \& Barrot, M. (2013). The amygdala between sensation and affect: A role in pain. Journal of Molecular Psychiatry, $1(1), 9$.

Wiech, K., Ploner, M., \& Tracey, I. (2008). Neurocognitive aspects of pain perception. Trends in Cognitive Sciences, 12(8), 306-313.

Wiech, K., \& Tracey, I. (2009). The influence of negative emotions on pain: Behavioral effects and neural mechanisms. NeuroImage, 47(3), 987-994.

Williams, J. M. G., Crane, C., Barnhofer, T., Brennan, K., Duggan, D. S., Fennell, M. J., Hackmann, A., Krusche, A., Muse, K., Von Rohr, I. R., Shah, G., Crane, R. S., Eames, C., Jones, M., Radford, S., Silverton, S., Silverton, S., Sun, Y., Weatherley-Jones, E., ... Russell, I. T. (2014). Mindfulness-based cognitive therapy for preventing relapse in recurrent depression: A randomized dismantling trial. Journal of Consulting and Clinical Psychology, 82(2), 275-286.

Williams, P. (2002), Buddhist thought. Taylor \& Francis.

Woo, A. K. (2010). Depression and anxiety in pain. Reviews in Pain, $4(1), 8-12$.

Yordanova, J., Kolev, V., Mauro, F., Nicolardi, V., Simione, L., Calabrese, L., Malinowski, P., \& Raffone, A. (2020). Common and distinct lateralised patterns of neural coupling during focused attention, open monitoring and loving kindness meditation. Scientific Reports, 10(1), 1-14.

Zeidan, F., \& Vago, D. R. (2016). Mindfulness meditation-based pain relief: A mechanistic account. Annals of the New York Academy of Sciences, 1373(1), 114-127.

Zeidan, F., Martucci, K. T., Kraft, R. A., Gordon, N. S., McHaffie, J. G., \& Coghill, R. C. (2011). Brain mechanisms supporting the modulation of pain by mindfulness meditation. Journal of Neuroscience, 31(14), 5540-5548.

Zeidan, F., Emerson, N. M., Farris, S. R., Ray, J. N., Jung, Y., McHaffie, J. G., \& Coghill, R. C. (2015). Mindfulness meditation-based pain relief employs different neural mechanisms than placebo and sham mindfulness meditation-induced analgesia. Journal of Neuroscience, 35(46), 15307-15325.

Zorn, J., Abdoun, O., Bouet, R., \& Lutz, A. (2020). Mindfulness meditation is related to sensory affective uncoupling of pain in trained novice and expert practitioners. European Journal of Pain, 24(7), 1301-1313.

Publisher's Note Springer Nature remains neutral with regard to jurisdictional claims in published maps and institutional affiliations. 


\section{Authors and Affiliations}

\section{Valentina Nicolardi ${ }^{1,2}$ - Luca Simione ${ }^{3} \cdot$ Domenico Scaringi $^{1} \cdot$ Peter Malinowski ${ }^{4}$ Juliana Yordanova ${ }^{5} \cdot$ Vasil Kolev $^{5}$.} Federica Mauro ${ }^{1} \cdot$ Fabio Giommi $^{6,7} \cdot$ Henk P. Barendregt $^{8} \cdot$ Salvatore M. Aglioti ${ }^{1,2} \cdot$ Antonino Raffone $^{1,9}$

1 Department of Psychology, Sapienza University of Rome, Rome, Italy

2 Social and Cognitive Neurosciences Laboratory, IRCCS, Santa Lucia Foundation, Rome, Italy

3 Institute of Cognitive Sciences and Technologies, CNR, Rome, Italy

4 School of Psychology, Research Centre for Brain and Behaviour, Liverpool John Moores University (LJMU), Liverpool, UK
5 Institute of Neurobiology, Bulgarian Academy of Sciences, Sofia, Bulgaria

6 AIM Italian Association for Mindfulness, Milan, Italy

7 Nous School of Psychotherapy, Milan, Italy

8 Faculty of Science, Radboud University, Nijmegen, The Netherlands

9 School of Buddhist Studies, Philosophy and Comparative Religions, Nalanda University, Rajgir, India 